Rhode Island College

Digital Commons @ RIC

Master's Theses, Dissertations, Graduate

Master's Theses, Dissertations, Graduate Research and Major Papers Overview

Research and Major Papers

$11-11-2017$

\title{
The Effect of Head Inclination on Intraocular Pressure in the Prone Position
}

Vanessa Marzilli

Follow this and additional works at: https://digitalcommons.ric.edu/etd

Part of the Nursing Commons

\section{Recommended Citation}

Marzilli, Vanessa, "The Effect of Head Inclination on Intraocular Pressure in the Prone Position" (2017).

Master's Theses, Dissertations, Graduate Research and Major Papers Overview. 257.

https://digitalcommons.ric.edu/etd/257

This Major Paper is brought to you for free and open access by the Master's Theses, Dissertations, Graduate Research and Major Papers at Digital Commons @ RIC. It has been accepted for inclusion in Master's Theses, Dissertations, Graduate Research and Major Papers Overview by an authorized administrator of Digital Commons @ RIC. For more information, please contact digitalcommons@ric.edu. 

THE EFFECT OF HEAD INCLINCATION ON INTRAOCULAR PRESSURE IN THE PRONE POSITION

A Major Paper Presented

by

Vanessa Marzilli

Approved:

Committee Chairperson

(Date)

Committee Members

(Date)

(Date)

Director of Master's Program

(Date)

Dean, School of Nursing

(Date) 
THE EFFECT OF HEAD INCLINCATION ON INTRAOCULAR PRESSURE IN THE PRONE

POSITION

by

Vanessa Marzilli

A Major Paper Submitted in Partial Fulfillment

of the Requirements for the Degree of

Master of Science in Nursing

in

The School of Nursing

Rhode Island College

2017 



\begin{abstract}
Postoperative vision loss (POVL) is a devastating complication of spine surgery in the prone position that may result in permanent blindness. Prone position is one of the major factors contributing to the development of increased intraocular pressure (IOP), which leads to POVL. The purpose of this systematic review was to determine the impact of head inclination on IOP in surgical patients positioned in the prone reverse Trendelenburg position compared to patients in the in the prone horizontal position. The CINHAL, EBSCOhost, Pubmed, Academic search complete, MEDLINE, Google scholar and Research Gate databases were utilized during this systematic review and the PRISMA 27-item checklist and four-phase flow diagram were used as well as the CASP tool for critically analyzing randomized controlled trials. Four studies met the inclusion and exclusion criteria and these studies were reviewed and analyzed in depth. Cross study analysis revealed that the reverse Trendelenburg position ameliorated increases in IOP in three out of four of the studies and IOP increased over time in three out of four of the studies. Certified registered nurse anesthetists (CRNAs) may decrease the patient's risk for POVL by maintaining the reverse Trendelenburg position during prone spine surgery and by using a tonometer device for measuring intraocular pressure. By adopting these new practices, CRNAs may provide the highest quality care for their patients.
\end{abstract}




\section{Table of Contents}

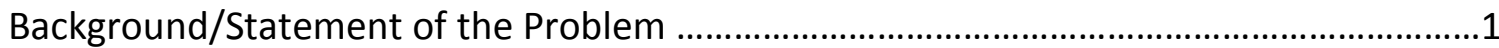

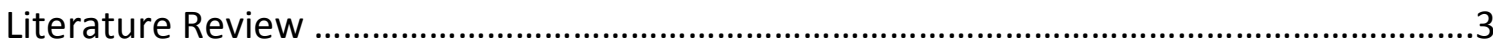

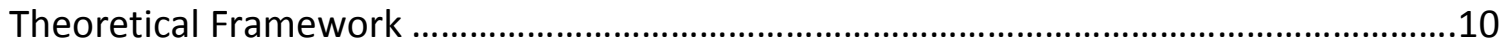

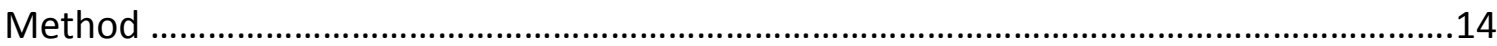

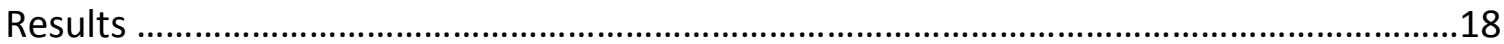

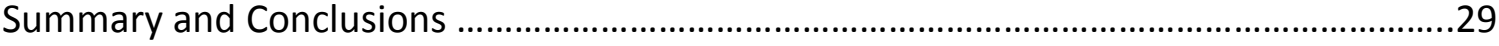

Recommendations and Implications for Advanced Nursing Practice ..............................33

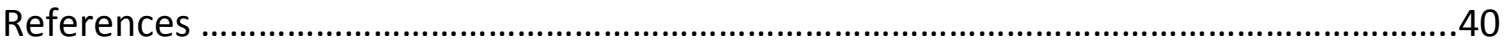

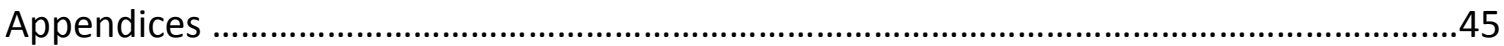


The Effect of Head Inclination on Intraocular Pressure in the Prone Position

\section{Background/Statement of the Problem}

Postoperative vision loss (POVL) is a rare complication of surgery that can be devastating for the patient. There are many factors that may contribute to the development of POVL including increased intraocular pressure (IOP) during surgery. The American Society of Anesthesiologist (ASA) Task Force on Perioperative Blindness (2006) explained that anesthesia providers should be well educated about the risk factors for POVL in order to decrease the incidence. Understanding the factors that contribute to increased intraocular pressure is important to decrease the risk of developing POVL.

Postoperative vision loss occurs most frequently during spinal surgery (Emery, Daffner, France, Ellison, Grose, Hobbs, \& Clovis, 2015). A systematic review by Kamel and Barnette (2014) explained the importance of intraoperative positioning of patients in the operating room. Kamel and Barnette cited that the prevalence rate of POVL associated with spine surgery was $0.0028 \%-0.2 \%$ and that prevalence has increased over the past several decades. Ischemic optic neuropathy (ION) is one of the most common causes of POVL (ASA Task Force on Perioperative Blindness, 2006). Ischemic optic neuropathy can occur as a result of increased IOP, which is defined as the pressure exerted by the contents of the eye on its containing wall (Kamel \& Barnette). Any external pressure on the eye can increase IOP. In addition to external pressure, fluid balance, arterial carbon dioxide tension, central venous pressure, peak airway pressure, duration of surgery and prone positioning have been shown to affect IOP (Kamel \& Barnette). 
One of the major factors in the development of IOP is the prone position (Walick, Kragh, Ward, \& Crawford, 2007). In the prone position, the patient is lying facedown, horizontal to the table, with the chest down and the back up. Even though prone position is a known risk factor for POVL, it is the most common position used for patients undergoing spine surgery. Advancements have been made in an effort to decrease pressure on the eyes such as head positioning in Mayfield pins and using foampositioning devices for the head. Further research must be conducted to explore the impact of alternative positions during spine surgery on the intraocular pressure. The purpose of this paper was to conduct a systematic review to determine the impact of head inclination on the IOP in surgical patients positioned in the prone reverse Trendelenburg position when compared to prone horizontal position.

Next, the review of the literature will be presented. 


\section{Literature Review}

\section{Postoperative Vision Loss}

Postoperative vision loss is a rare surgical complication that may result in permanent vision loss for the patient. According to the ASA, POVL is characterized by permanent impairment or total loss of vision associated with a spine procedure during which general anesthesia is administered (2006). Therefore, POVL is a serious, life changing, adverse surgical outcome. There are many factors that may contribute to the development of POVL, though the exact cause is unknown (Molloy, 2012). Research has focused on determining the risk factors for the development of POVL.

Risk Factors for POVL. Risk factors associated with POVL include hypotension, blood loss, anemia, hypovolemia, hypoxia, hemodilution, facial edema, pressure on the eye, use of vasopressors, prone and head-down positions, substantial fluid resuscitation, increased venous pressures and prolonged surgery (ASA, 2006). In the retrospective review by Roth, Thisted, Erickson, Black, and Schreider (1996), risk factors for ocular injury included lateral or prone positioning, increased age, head and neck procedures, general anesthesia, long surgical procedures, and surgery on a Monday.

A retrospective review by Chang and Miller (2005) examined 14,102 cases over a 20-year period. Of the 14,102 cases, four patients were found to have discharge diagnoses of posterior ischemic optic neuropathy (PION), an incidence of $0.028 \%$. Of the four patients who developed PION during spine surgery, all were found to be anemic during surgery. Also, three of the four patients became hypotensive with systolic blood pressures less than $90 \mathrm{~mm}$ hg with reductions in mean arterial pressures. The authors 
suggested that anemia, hypotension, long surgical duration, and significant intraoperative fluid hydration might be risk factors for the development of vision loss.

A review of 93 cases of POVL by Lee et al. (2006) examined the potential risk factors of patients who developed POVL. Ischemic optic neuropathy (ION) was found to be the cause of vision loss in $89 \%(n=83)$ of the cases. The authors found blood loss greater than $1,000 \mathrm{ml}$ occurred in $83 \%$ of cases, and anesthetic duration greater than 6 hours was present in $94 \%$ of cases. A retrospective review by Holy, Tsai, McAllister, and Smith (2009) attempted to determine hemodynamic factors leading to POVL in 17 patients with perioperative ischemic optic neuropathy. Factors examined included age, body mass index, medical history, mean arterial pressure, hematocrit, blood products administered, blood loss amount, lowest body temperature, surgery time, and vasopressors. In contrast to the previous studies, Holy et al. found that there was no difference in hemodynamic variables between individuals who developed POVL and those who did not develop POVL. The authors compared the patient cases of ION to the cases without ION and reported no statistical significance in the variables examined between the two groups. These results suggested that ION might develop without signs of hemodynamic instability during the perioperative period.

In 2012, The Postoperative Visual Loss Study Group completed a case-control examination of 80 patients with ION from the ASA Postoperative Visual Loss registry compared to 315 control subjects. The subjects had each undergone spinal fusion surgery and the subjects were randomly selected from 17 different institutions. Risk 
factors for ION included obesity, male gender, Wilson frame use, greater estimated blood loss, longer anesthetic duration and lower percent colloid administration (The Postoperative Visual Loss Study Group). Because of the contrasting results of the studies, it remains unclear as to the definitive contributors to the development of POVL.

Incidence of POVL. Research by Roth et al. (2006), which examined factors leading to the development of POVL, found an incidence of eye injury in non-ocular surgery of $0.056 \%$. In an effort to examine a large population of patients who had spine surgery, Chang and Miller (2005) completed a retrospective review of 14,102 spine surgeries over a period of 20 years. From these spine surgeries, 46 cases were found in which visual impairment was coded in the discharge diagnosis. Out of these 46 cases, only four were determined to be associated with perioperative ischemic optic neuropathy (PION), an incidence of $1.8 \%$. These four cases were categorized by vision loss in one eye that was not present prior to surgery. Three of these cases involved patients who underwent spine surgery in the prone position and one case involved a patient who underwent spine surgery in the lateral decubitus position.

Kitaba, Martin, Gopalakrishnan and Tobias (2013) reviewed 10 studies from 1996-2012 that examined the incidence of POVL in patients undergoing nonocular surgery, cardiac surgery, spine surgery, and surgery in general. The incidence of POVL ranged from $0.056-1.3 \%$, with the highest risk occurring during spinal and cardiac surgery. In a study by Kamel and Barnette (2014), the prevalence rate of POVL associated with spine surgery was discovered to be $0.0028 \%-0.2 \%$. 
Causes of ION. Vision loss resulting from spine surgery may develop due to ION, central retinal artery occlusion, cortical blindness and posterior reversible encephalopathy (Emery et al., 2015). For purposes of this research, ION will be discussed in further detail. Ischemic optic neuropathy (ION) is a rare complication of surgery in the prone position. According to Molloy, ION is caused by hypoperfusion and hypoxia of the optic nerve (2011). Ischemic optic neuropathy may affect either the anterior or posterior portion of the optic nerve. Anterior ischemic optic neuropathy, or AION, may be caused by occlusion or hypoperfusion of the anterior optic nerve head by the posterior ciliary artery (Nickels, Manlapaz, \& Farag, 2014). Posterior ION results from infarction of the optic nerve posterior to the lamina cribrosa (Nickels et al., 2014). Decreased perfusion to the anterior optic nerve may cause nerve damage and eventually blindness.

\section{Prone Positioning and Intraocular Pressure}

Prone positioning increases IOP, which decreases perfusion pressure to the optic nerve (Walick et al., 2007). High intraocular pressure (IOP) has been shown to decrease ocular perfusion pressure, thus causing decreased perfusion to the anterior optic nerve. Elevated IOP may also cause compression of the optic nerve, which can lead to nerve fiber damage and death (Hall, 2016). According to Hall, the normal intraocular pressure of the eye is about $15 \mathrm{~mm} \mathrm{Hg}$, but can range from 12 to $20 \mathrm{~mm} \mathrm{Hg}$. Intraocular pressures of 20 to $25 \mathrm{~mm} \mathrm{Hg}$ may cause vision loss and extremely elevated pressures 
may lead to permanent blindness (Hall). Research has been performed to analyze IOP in surgical patients in the prone and supine positions.

Cheng, Todorov, Tempelhoff, McHugh, Crowder, and Lauryssen compared IOP in 20 patients undergoing spine surgery in the prone and supine position at different time intervals throughout the procedure (2001). The patients' IOP was measured with a hand-held Tono-pen XL tonometer, which is a device used to measure the pressure inside the eye. The patients' baseline IOP was measured prior to premedication, 10 minutes after intubation in the supine position, before incision in the prone position, at conclusion of surgery in the prone position and when the patient was placed in supine position at the end of the procedure. The results of this study showed that in the 20 patients, IOP significantly increased $(P<0.05)$ when the anesthetized patient was placed in prone position $(27 \mathrm{mmHg}$ ) and IOP continued to increase when the patient remained in the prone position for longer periods of time $(40 \mathrm{mmHg})$. This was the first study to measure IOP in prone anesthetized patients (Cheng et al.).

In 2011, Agah, Ghasemi, Roodneshin, Radpay, and Moradian examined 20 patients undergoing percutaneous nephrolithotomy in the prone and supine position. Intraocular pressure was measured at five different intervals. The intraocular pressure was measured by a Tono-pen at baseline, 10 minutes after anesthesia, 10 minutes after position change to prone, at the end of the procedure in prone position and 10 minutes after position change to supine position. The results showed an average increase in IOP of $13 \mathrm{mmHg}$ for all patients 10 minutes after position change from supine to prone and 
an increase in IOP of about $26.4 \mathrm{mmHg}$ (compared to supine position) at the end of the procedure in prone position. Intraocular pressure changed significantly in five positions $(P=.000)$ and there was a linear relationship between IOP and prone position duration. These results demonstrated that prone position dramatically increased IOP, which decreased the perfusion pressure to the anterior optic nerve and may lead to POVL and possibly blindness.

Yoshimura, K., Hayashi, H., Tanaka, Y., Nomura, Y., and Kawaguchi, M. (2015) measured the IOP in 56 patients undergoing spine surgery in the prone position. The patients were over the age of 18 and underwent general anesthesia. Patients who had glaucoma and ophthalmic disease were excluded from the study. Intraocular pressure (IOP) was measured with a hand-held tonometer and measurements were taken 10 minutes after induction of anesthesia in the supine position as well as every 60 minutes after placing the patient in the prone position. Results showed that IOP increased greater than $30 \mathrm{mmHg}$ in 20 of the 56 patients (35.7\%) undergoing spine surgery in the prone position. Also, IOP measurements of greater than $23 \mathrm{mmHg}$ one hour after prone positioning were a predictor for increased IOP of greater than $30 \mathrm{mmHg}$. This finding indicated that the measurement of IOP with a tonometer at an early time point during the operation might be used as a predictor of high IOP in anesthetized patients. According to Yoshimura et al., prediction of an IOP increase may provide an opportunity for preventative strategies such as head-up positioning, shortening the operating time, and fluid restriction. 


\section{Recommendations for Evidence Based Practice}

Due to the high incidence of elevated IOP in patients undergoing spine surgery in the prone position, Yoshimura et al. (2015) suggested that measurement of IOP one hour after prone positioning may provide an opportunity to treat and intervene in subsequent IOP increases. However, use of the tonometer to measure IOP during surgery may not be feasible due to the inability of the nurse anesthetist to reach the eyes during surgery, the education required to use the tonometer, the cost of the technology and the potential for injury to the eye if the tonometer is used incorrectly. Due to the evidence from Cheng et al. that IOP increased in the prone position, it was suggested that a head-neutral or head-up position might attenuate the observed IOP increase in the prone position (2001).

Because of the increased incidence of POVL in the prone position, The ASA Task Force on Perioperative Blindness developed a practice advisory for patients undergoing spine surgery in the prone position (2011). The ASA recommended that patients should be positioned so that the head is level with or higher than the heart when possible. In response to the suggestion that head inclination, or head-up positioning, may decrease IOP, various studies have been conducted that examine the effect of head positioning on intraocular pressure. The results of these studies will be examined in the systematic review.

Next, the theoretical frameworks guiding this review will be presented. 


\section{Theoretical Framework}

The Preferred Reporting Items for Systematic Reviews and Meta-Analyses, or PRISMA statement, was designed in 2005 to help authors improve the reporting of systematic reviews and meta-analyses. The PRISMA statement includes a 27 -item checklist and four-phase flow diagram (Moher, Liberati, Tetzlaff, Altman, \& the PRISMA Group, 2009). The checklist and four-phase flow diagram were designed to provide for a method of research, while decreasing researcher bias in the process of completing a systematic review or meta-analysis.

The PRISMA statement originated from the Quality of Reporting of Metalanalyses, or QUOROM Statement, which was developed in 1996 in response to inadequate reporting of meta-analyses. It focused on the reporting of meta-analyses of randomized controlled trials, with the intent of improving quality assessment of studies and reporting. In 2005, the framework was changed from QUOROM to PRISMA to include systematic reviews as well as meta-analyses.

In 2011, a meeting was held to develop a protocol for developing systematic reviews. This protocol was known as the Preferred Reporting Items for Systematic Reviews and Meta-Analyses Protocols, or PRISMA-P. The PRISMA-P provides a guideline to improve the transparency, completeness, accuracy, and frequency of systematic review and meta-analysis protocols. Elements from an internal register for prospective reviews (PROSPERO), the PRISMA checklist, Standard Protocol Items: Recommendations for Interventional Trials (SPIRIT) checklist items, and Standard 2.6 from the Institute of 
Medicine's Standards for Systematic Reviews were included in the PRISMA-P checklist (Shamseer et al., 2015).

The PRISMA-P checklist consists of 17 items and 26 sub-items. The three main sections of the checklist include administrative information, introduction and methods. The sub-items include: title; registration; authors; amendments; support; rationales; objectives; eligibility criteria; information sources; search strategy; study records; data items; outcomes and prioritization; risk of bias in individual studies; data synthesis; meta-bias; and confidence in cumulative evidence. The PRISMA-P checklist was designed to overlap with the PRISMA checklist in order to facilitate a smooth transition from PRISMA to PRISMA-P. The PRISMA-P, unlike PRISMA, does not contain a flow diagram documenting the flow of studies throughout the systematic review process (Moher et al., 2015). However, it is important to include documentation of the PRISMA flow diagram once the systematic review has been carried out.

Benefits of adhering to the PRISMA-P checklist include improved quality, completeness, and consistency of protocol content (Moher et al., 2015). It enables reviewers to anticipate and avoid future changes to review methods, increases awareness of minimum content for protocol reporting, and improves completeness of reporting completed reviews (Moher et al.). For the purpose of this systematic review, the PRISMA-P 2015 checklist will be used to assure that key components are reviewed and considered in the review. The flow diagram illustrated on the next page (Figure 1) will be used to document the selection and review of research studies. 


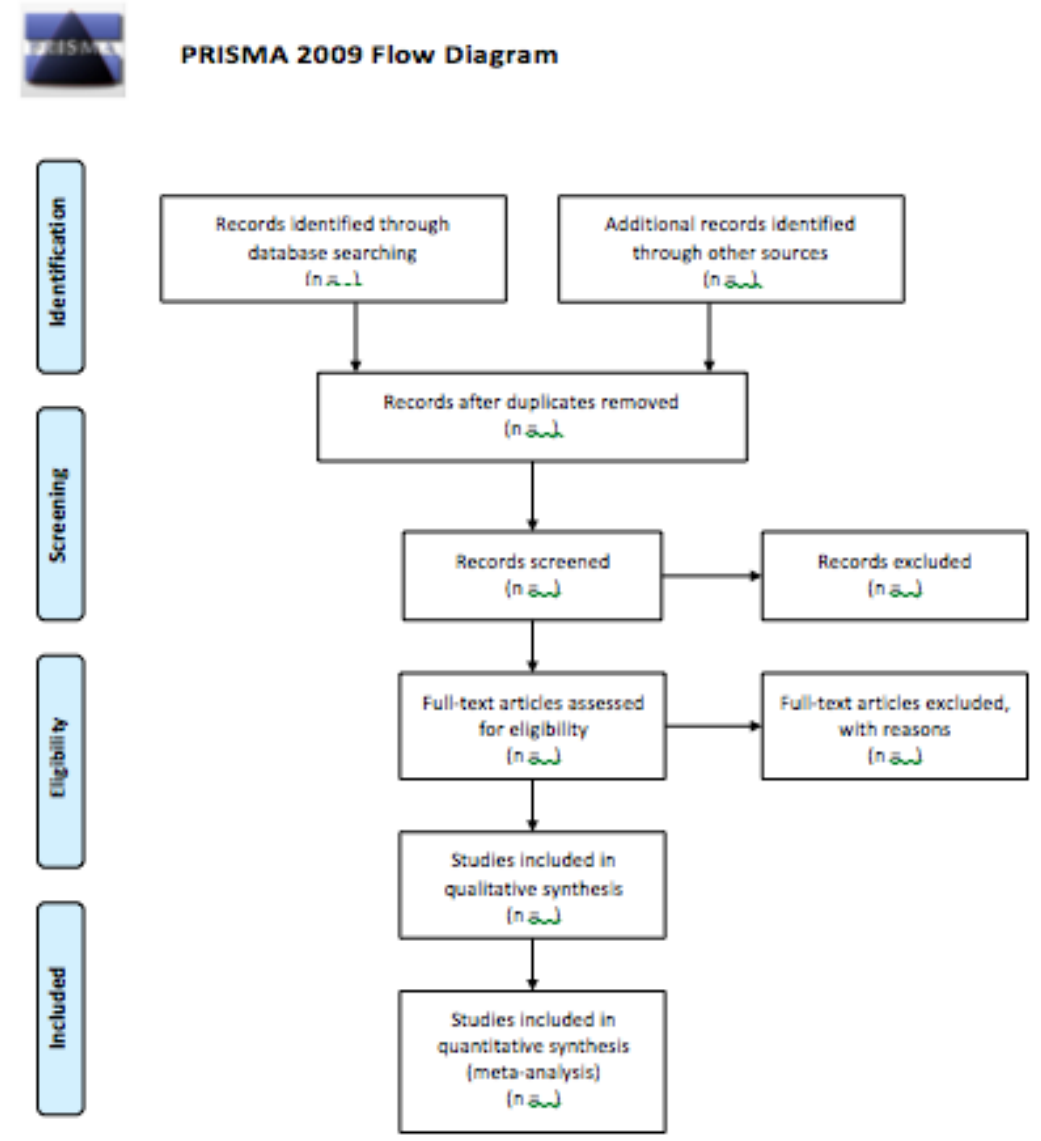

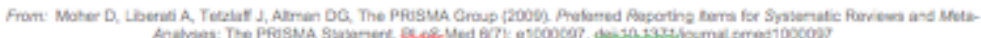

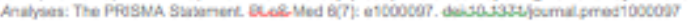

Figure 1. PRISMA Flow Diagram. This figure illustrates the number of records identified, included and excluded, and the reason for exclusions.

In order to assess the trustworthiness and overall quality of the randomized control trials, the Critical Appraisal Skills Program (CASP) for Randomized Control Trials tool will be utilized. CASP is used to determine the validity of the study, the results, and the usefulness of the results of a study (CASP, 2017). The CASP tool includes 11 questions as presented in Appendix B. 
The researcher may answer "yes", "no", or "can't tell" in response to each of the questions. Reference for the CASP tool is provided in Appendix B. Elements to consider are listed below each question in order to guide the researcher and the researcher is encouraged to record reasons for answers in the spaces provided under the questions.

The CASP measure will also be used to assess across studies. Data synthesis will be accomplished by examining the main outcomes of the studies by looking across the studies to find the similarities, differences, draw conclusions, and determine if the studies support each other. The studies will be evaluated, and emerging themes across the studies will be explored.

Next, the methods section will be presented. 


\section{Method}

\section{Purpose/ Outcomes}

The purpose of this systematic review was to determine the impact of head inclination on surgical patients positioned in the prone reverse Trendelenburg position compared to no incline. Outcomes examined included the level of intraocular pressure after surgery in the prone position without incline compared to the level of intraocular pressure after surgery in the prone position in reverse Trendelenburg position. Other outcomes examined included patient position, duration of procedure, duration of time in each position and baseline IOP.

\section{Inclusion/ Exclusion Criteria / Limits}

Inclusion criteria included use of the tonometer as a measuring device to measure intraocular pressure, patients greater than 18 years of age, randomized controlled trials or pilot studies, patient head positioned in reverse Trendelenburg position compared to no incline, prone position, and baseline IOP measurements. The Tonometer will measure intraocular pressure in each of the trials. The intraocular pressure of patients in the prone position will be measured. Trials may include patients undergoing any type of surgery in the prone position, as well as patients in the prone position who are not undergoing surgery. Included research must be peer reviewed and available in the English language. 
Exclusion criteria included patients with glaucoma, in supine or lateral decubitus position, trials examining head rotation, trials involving pediatric patients under the age of 18 years

\section{Detailed Search Strategy}

A comprehensive search of quantitative literature was conducted using the following keywords: "Ischemic Optic Neuropathy", "Surgery", "Prone", "Trendelenburg", "Position", "Postoperative Vision Loss", "Tonometer", "Increased Intraocular Pressure", "Intraocular Pressure". CINAHL, EBSCOhost, Pubmed, Academic search complete, MEDLINE, Google scholar, and Research Gate will be utilized for an in depth literature search. Randomized control trials were included in the search, as well as abstracts from professional medical journals. The articles must have been written in the English language. Articles in languages other than English will be excluded. Articles published between the years 2000 and 2016 were included in the search. The PRISMA flow diagram was utilized to decrease bias and improve the transparency, completeness, and accuracy of the systematic review.

\section{Data Collection}

Data were collected through utilization of a data collection table created by the researcher. Two tables were utilized. The first includes general information about each study, including the study design, type of surgery, number of participants, positions compared, and limitations. The second includes key outcomes including baseline IOP, the time intervals at which IOP was measured, IOP measurements, variables and 
outcomes examined, and findings in prone and reverse Trendelenburg position. The two data collection tables are illustrated below.

Table I

Data Collection Tool 1

\begin{tabular}{|c|c|c|c|c|c|c|}
\hline Purpose & $\begin{array}{l}\text { Study } \\
\text { Design }\end{array}$ & $\begin{array}{l}\text { Sample and } \\
\text { subject } \\
\text { demographic }\end{array}$ & Method & $\begin{array}{l}\text { Positions } \\
\text { compared }\end{array}$ & Measurement & $\begin{array}{l}\text { Data } \\
\text { Analysis }\end{array}$ \\
\hline & & & & & & \\
\hline & & & & & & \\
\hline & & & & & & \\
\hline & & & & & & \\
\hline
\end{tabular}

Table 2

Data Collection Tool 2

\begin{tabular}{|c|c|c|c|c|}
\hline Baseline IOP & $\begin{array}{l}\text { Variables/ } \\
\text { Outcomes } \\
\text { examined }\end{array}$ & $\begin{array}{l}\text { IOP measurements } \\
\text { in each interval }\end{array}$ & $\begin{array}{l}\text { Findings prone/ } \\
\text { reverse } \\
\text { Trendelenburg }\end{array}$ & Limitations \\
\hline & & & & \\
\hline & & & & \\
\hline & & & & \\
\hline & & & & \\
\hline
\end{tabular}




\section{Assessment Criteria/Critical Appraisal Tools/ Quality Assessment}

In order to assess the trustworthiness, relevance, and results of the randomized control trials, the Critical Appraisal Skills Program (CASP) for Randomized Control Trials tool was utilized. CASP is used to determine the validity of the study, the results, and the usefulness of the results of a study (CASP, 2017). Each randomized control trial was evaluated individually using the CASP tool, and results will be reported within the review.

\section{Data Synthesis}

Data synthesis is accomplished by examining the main outcomes of the studies by looking across the studies to find the similarities, differences, draw conclusions, and determine if the studies support each other. After evaluating the data from Table 1 and Table 2 , the best practices for decreasing IOP in prone position were examined and explained. 


\section{Results}

Four studies met the inclusion criteria for this systematic review. In the study by Ozcan et al. (2004), 10 subjects were recruited (Appendix C1), classified as ASA I or II. Each subject was evaluated at two separate sessions: the first with a Jackson table and the second with the Wilson frame. Intraocular pressure (IOP) was measured by the Tono-Pen after five minutes spent in each of the following positions: sitting upright (sitting); supine on a horizontal OR table (supine); prone on a horizontal OR table (prone-horizontal 1); prone with a $10^{\circ}$ reverse Trendelenburg position (prone-head up); prone with a $10^{\circ}$ Trendelenburg position (prone-head down); and prone with the table back to horizontal (prone-horizontal 2). Other variables examined were heart rate, blood pressure, and the Jackson table vs. Wilson frame. Additional information about the study's purpose, design, sample, method, etc. may be found in Appendix C1.

The results demonstrated (Appendix D1) that IOP in the $10^{\circ}$ reverse Trendelenburg position was $2.2 \mathrm{~mm} \mathrm{Hg}$ lower than IOP in the prone horizontal position and $3.5 \mathrm{~mm} \mathrm{Hg}$ lower than IOP in Trendelenburg position. The authors concluded that a $10^{\circ}$ reverse Trendelenburg ameliorated the increase in IOP caused by the prone position in awake subjects $(P<0.001)$.

The critical analysis of the Ozcan et al. study is illustrated in Appendix E1 using the CASP tool. The study was a randomized crossover study that set forth to determine the effect of table inclination on IOP; even though this study was not a randomized control trial, it has a high level of evidence because it was a randomized crossover study 
where the subjects participated in two sessions in which the table inclinations and time spent in each inclination remained the same. It was not possible for the subject to manipulate the changes in IOP due to position changes and therefore lack of blindness of the subjects in this study was not significant. The researchers were not blinded in this randomized crossover study. All of the subjects who entered the study were accounted for at the end of the study, and all of the subjects met the inclusion and exclusion criteria outlined in Appendix C1. The results of this study were of clinical importance to this systematic review because they showed the effect that different table inclinations had on IOP. The authors also examined two different table setups, heart rate, and MAP which were found to be clinically insignificant to the study. Even though the results of this study were of clinical importance, the subjects remained awake during the sessions, which did not allow for a representation of anesthetic effects on IOP in the prone position. The benefits of this study outweigh the harms because none of the subjects suffered injury such as corneal abrasion after the sessions and the study was low risk or injury.

In a study by Grant et al. (2010), the effect of four-degree reverse Trendelenburg prone position on IOP was compared to the effect of horizontal prone position on IOP (Appendix C2). Ten subjects, ASA physical status I and II, were recruited for the study. Inclusion and exclusion criteria may be found in Appendix C2. Each subject was evaluated at two separate sessions: the first on a horizontal table in prone position, and the second in four-degree reverse Trendelenburg position. Intraocular Pressure was measured using a Tono-pen XL applanation tonometer at nine different intervals during 
each of the two sessions: supine position; prone position; hourly for five hours in the prone position; on return to supine position; and 30 minutes in the supine position. Other variables examined include MAP, choroidal thickness, and optic nerve diameter. Addition information about the Results of the study may be found in Appendix D2.

The authors found that there was a greater increase in IOP in the reverse Trendelenburg position compared to the horizontal position. There was a significant effect of time on the increase of IOP, choroidal thickness, and optic nerve diameter. The authors concluded that four degrees of table inclination might not attenuate the rise of IOP in the prone position $(\mathrm{P}<0.01)$.

The critical analysis of the Grant et al. study is illustrated in Appendix E2 using the CASP tool. This study was a small pilot study that set forth to evaluate the effect of prone position and a four degree increase in table inclination on IOP. Even though the authors did not indicate whether or not the subjects or researchers were blinded, the subjects had no control over positioning or the results of the IOP measurements. Therefore, subject and researcher blindness in this study was not of extreme significance because it would not have changed the outcome of the study. The subjects were similar at the start of the trial, and all of the subjects were accounted for at the end of the study. For the most part, the subjects were treated equally throughout the study. The only difference was that the final eight subjects concluded their prone session with a rest period of 30 minutes in the supine position and the first two subjects did not. The 30 minute rest period was implemented to evaluate any additional changes 
that might have occurred in a clinically relevant position routinely used in a recovery room. This change did not affect the IOP measurements prior to the rest period. The results of the study were of clinical importance to this systematic review because they represent the changes seen in IOP over time and with four degree head inclination. Contrary to spine surgery under general anesthesia, the subjects were awake while in prone position, which did not provide surgical controls or represent IOP changes under general anesthesia. Even though the subjects complained of sinus congestion and chest discomfort during the final hour of the study, the symptoms resolved within 24 hours. Therefore, the study was low risk and the benefits of the study outweighed the risks.

A third study by Carey, Shaw, Weber, and DeVine compared three different prone position inclinations to determine their effect on IOP (Appendix C3). Twenty-one subjects undergoing spine surgery were randomized into one of three prone positions: neutral; five-degree reverse Trendelenburg; and 10 degree reverse Trendelenburg. Intraocular pressure was measured using a Tono-pen XL at five different intervals: preinduction; 30 minutes after induction in supine position; 30 minutes after prone positioning; 60 minutes after prone positioning; and every hour after. Other variables measured included MAP, estimated blood loss, and fluid resuscitation. Additional information about the study may be found in Appendix C3.

The authors found that in the neutral position group, $57.14 \%$ of subjects experienced at least one measurement of IOP above $30 \mathrm{mmHg}$. Subjects in the fivedegree $(P=.05)$ and 10-degree $(P=.002)$ reverse Trendelenburg positions did not 
experience IOP above $30 \mathrm{mmHg}$. Results of the study may be found in Appendix D3. The authors concluded that reverse Trendelenburg position decreased IOP when compared to neutral prone position for surgery that lasted 120 minutes or less. In addition, IOP had a slower rate of increase in subjects in reverse Trendelenburg position compared with neutral prone position.

The critical analysis of the Carey et al. study is illustrated in Appendix E3 using the CASP tool. The study was a single center prospective randomized controlled study. The study's purpose was to assess the effect of three different table inclinations on IOP. Subjects were randomized into three inclination groups using a random number generator and the subjects were blinded as to which positioning group they participated. The surgeon was unable to be blinded due to the circumstances of the study. Twenty-one subjects were present at the beginning of the study; however, two subjects were excluded due to failure of the tonometer battery. All of the subjects met the inclusion criteria outlined in Appendix E3 and all of the subjects were treated equally. The results of the study were of clinical importance to this systematic review because they demonstrate the relationship between head inclination and IOP. The subjects in the study underwent spine surgery under general anesthesia, which correlates directly with the target population of this systematic review. Because the IOP measurements were taken with the patient under general anesthesia, the measurements more accurately accounted for the changes in IOP in the surgical patient. One subject developed a corneal abrasion postoperatively, however no ophthalmic 
complications occurred as a result of the corneal abrasion. Therefore, the benefits of this study outweighed the risks.

In the final study by Emery et al., the authors compared two different head positions and their effect on IOP (Appendix C4). Sixty-three subjects were randomized into two different groups: group 1 underwent surgery with the head in neutral position and group 2 underwent surgery with the head in a 10-degree angle of inclination in relation to the table. Both groups underwent surgery in the prone position. Additional information about the study and positioning may be found in Appendix C4. Intraocular pressure was measured using an applanation tonometer in the following positions and intervals: sitting; supine following induction; five minutes after prone positioning; and every 15 minutes during the operation until three readings in a row were within 3 $\mathrm{mmHg}$ of each other. An hour later, the measurements were taken again. Other factors examined included duration of surgery, amount of crystalloid and colloids infused, estimated blood loss, transfusion amount and the subject's gender. Refer to Appendix D4 for results of the study.

According to the authors, the mean change in IOP measurements were significantly lower in group II than in group I $(p=0.0074)$. There was also a general rise in IOP in groups I and II over time. The authors concluded that the duration of surgery was the only factor that significantly influenced the change in IOP over time in each group. 
The critical analysis of the Emery et al. study is illustrated in Appendix E4 using the CASP tool. This study was a randomized, prospective trial that set forth to measure the effect of 10-degree head elevation on IOP in patients undergoing lumbar fusion. Subjects were randomized using a random list of numbers generated by a statistician. Sixty-three subjects were enrolled in the study; however 11 of the subjects were dropped from the study. Reasons for the exclusion of the 11 subjects was detailed by the authors and can be found in Appendix E4. The remaining subjects met inclusion and exclusion criteria and there were no significant demographic differences between groups I and II. The subjects in the study were blinded, and the subjects were treated equally throughout the study. To ensure consistency, only four anesthesiologists were involved in the study and only one technician obtained all IOP measurements with the application tonometer. The results of the study were of clinical important to this systematic review, as the main outcome measure was IOP. Other variables that were measured may be found in Appendix E4. Because the subjects underwent spine surgery in prone position under general anesthesia, the results are a realistic representation of the effect of head inclination on IOP in the clinical setting. None of the subjects developed vision loss or cervical spine related complications. However, one patient developed a mild corneal abrasion that resolved in 24 hours. Therefore, the benefits of this study outweighed the risks.

Cross study analysis. The four studies examined in this systematic review were similar in that each of the studies evaluated IOP in relation to subject positioning on an operating room table. However, there were differences in the methods and outcomes of 
each study. Two of the studies were not randomized control trials: the study by Ozcan et al. was a randomized crossover study, and the study by Grant et al. was a small pilot study. These studies included a small group of ten subjects. In contrast, the studies by Carey et al. and Emery et al. were randomized controlled trials. The study by Carey et al. included 21 subjects, and the study by Emery et al. included 63 subjects. The larger subject groups and randomized methods improved the validity of those studies. Even though the studies by Ozcan et al. and Grant et al. were not randomized controlled trials, they were included in this systematic review due to the paucity of studies on the topic.

In the first two studies by Ozcan et al. and Grant et al., neither the researchers nor the subjects were blinded. The subjects were unable to be blinded because they were awake during study. In the study by Carey et al., the subjects were randomized into different groups using a random number generator and they were blinded as to which group they were participating in. However, the researchers were not blinded. In the study by Emery et al., subjects were randomized and blinded throughout the study. In the Emery et al study, only four anesthesiologists measured intraocular pressure (IOP) in the study to maintain consistency. This was the only study in which there was an effort to maintain consistency during measurement of IOP.

In each of the four studies, IOP was measured by an applanation tonometer. Intraocular pressure was measured in all of the studies during some degree of head elevation. Ozacan et al. measured IOP in the 10-degree reverse Trendelenburg position, 
Grant et al. in the four degree reverse Trendelenburg position, Carey et al. in the fivedegree and 10-degree reverse Trendelenburg position, and Emery et al. in a 10-degree head inclination to the table. Also, IOP measurements were taken at different intervals and after differing lengths of time in each position.

The studies by Carey et al. and Emery et al. were most representative of the population affected in the clinical setting because the subjects underwent spine surgery in the prone position under general anesthesia. By measuring IOP of subjects undergoing surgery under general anesthesia, the authors were able to evaluate changes in IOP in relation to position and effects of general anesthesia. General anesthesia may affect IOP due to changes in ocular perfusion, IV fluid administration, blood loss, and hemodynamic instability. Therefore, the studies by Carey et al. and Emery et al. correlate most closely with the target population of this systematic review.

There were interesting differences in the outcomes of each of the studies. Ozcan et al. found that the reverse Trendelenburg position ameliorated the increase in IOP caused by prone positioning. In contrast to these findings, Grant et al. found an increase in IOP in the reverse Trendelenburg position compared to the prone horizontal position, with an increase in IOP over time $(p<0.05)$. The percentage increase of IOP from baseline in the prone horizontal subjects after 5 hours prone was $141 \%$ compared to 178\% in the four-degree reverse Trendelenburg position. Carey et al., similarly to the study by Ozcan et al., found that reverse Trendelenburg positioning decreased IOP when compared to prone positioning. After 60 minutes in the prone horizontal position, five- 
degree reverse Trendelenburg position, and 10-degree reverse Trendelenburg position, the mean IOP measurements were $26.33,23.17$, and 21.42 respectively. The study also found that subjects in the five and 10-degree reverse Trendelenburg position has a slower rate of increase in IOP. Emery et al. also found that a 10-degree head elevation lowered the mean changes in IOP measurements. The mean change in IOP measurements were significantly lower in the 10-degree head elevation group (9.26 $\mathrm{mmHg}$ ) than in the prone horizontal group $(13.79 \mathrm{mmHg})$, with a difference of 4.53 $\mathrm{mmHg}$ between groups $(\mathrm{p}>0.0074)$.

Three out of four of the studies in this systematic review concluded that rate of rise of IOP was either slowed or ameliorated in subjects with some degree of head elevation. The study by Grant et al. showed an increase in IOP in the reverse Trendelenburg position, but also found an increase in IOP over time (Appendix D2). Three of the four studies found an increase in IOP over time. There are many similarities and differences across the four studies, but one can conclude that IOP increases over time and may be ameliorated by reverse Trendelenburg position or head elevation. Table 3 on the next page compares each of the studies major findings, including whether or not head elevation ameliorated the rise in IOP and whether or not IOP increased over time. 
Table 3

Key Findings re: IOP

\begin{tabular}{|c|c|c|}
\hline & Head elevation ameliorated the rise in & IOP increased over time \\
\hline Ozcan et al. & IOP & Not measured \\
\hline Grant et al. & No & Yes \\
\hline Carey et al. & Yes & Yes \\
\hline Emery et al. & Yes & Yes \\
\hline
\end{tabular}

Next, summary and conclusions will be discussed. 


\section{Summary and Conclusions}

Postoperative vision loss (POVL) is a devastating complication of surgery that may result in permanent blindness in the patient. Postoperative vision loss occurs most frequently during spine surgery (Emery et al., 2015) and has a prevalence of $0.0028 \%$ 0.2\% (Kamel \& Barnette, 2014). Increased intraocular pressure (IOP) leads to ischemic optic neuropathy, which is the most common cause of POVL (ASA Task Force on Perioperative Blindness, 2006). Prone position is one of the major factors in the development of increased IOP (Walick et al., 2007) and prone position is used most commonly during spine surgery due to surgical exposure. Many authors have evaluated the effect of prone position on IOP (Agah et al., Cheng et al., Yoshimura et al.) and documented that IOP increases after prone positioning. Therefore, the ASA Task Force on Perioperative Blindness (2006) recommended that patients be positioned with the head level with or higher than the heart when possible. Despite these recommendations, patients continue to undergo spine surgery in the prone horizontal position, putting them at risk for POVL.

The purpose of this systematic review was to determine the impact of head inclination on intraocular pressure in surgical patients positioned in the prone reverse Trendelenburg position compared to patients in the prone horizontal position. The CINHAL, EBSCOhost, Pubmed, Academic search complete, MEDLINE, Google scholar and Research Gate databases were utilized during this systematic review. The PRISMA 27item checklist and four-phase flow diagram were followed in order to provide for a 
method of research while decreasing bias during the systematic review process. Three randomized control trials and one pilot study were included in this review. Data were collected and organized by the author through use of a data collection tool (Table 1 and Table 2). Critical analysis and cross study analysis was completed using The Critical Appraisal Skills Programme (CASP) Randomized Controlled Trials Checklist (Appendix B) and this author's identified methodology.

Through evaluation and critical analysis of the four studies, two themes became apparent: that head elevation either did or did not ameliorate the rise in intraocular pressure (IOP), and IOP either did or did not increase over time. Originally, the only variable in this systematic review was IOP change in prone reverse Trendelenburg position versus prone horizontal position. However, the author of this systematic review was surprised to see that in three out of four of the studies, IOP increased over time; in one study, the effect of IOP over time was not measured (Ozcan et al., 2004).

Intraocular pressure (IOP) was ameliorated by the reverse Trendelenburg or head elevated position in the studies by Ozcan et al. (2004), Carey et al. (2013) and Emery et al. (2015). Ozcan et al. (2004) found that IOP decreased from an average of $22.5 \mathrm{~mm} \mathrm{Hg}$ in the prone horizontal position to an average of $20.3 \mathrm{~mm} \mathrm{Hg}$ in the reverse Trendelenburg position. Carey et al. determined that after 60 minutes in the prone position, IOP was $26.33 \mathrm{~mm} \mathrm{Hg}$ in subjects lying the horizontal prone position compared to an IOP of 23.17 in the 5-degree reverse Trendelenburg position $(p=.05)$ and $21.42 \mathrm{~mm}$ $\mathrm{Hg}$ in the 10-degree reverse Trendelenburg position $(p=.002)$. In the randomized control 
trial by Emery et al., the subjects who remained in the horizontal prone position had overall IOP values of $27.59 \mathrm{~mm} \mathrm{Hg}$, and subjects in the 10-degree head elevation position had overall IOP values of $23.33 \mathrm{~mm} \mathrm{Hg}(\mathrm{p}=0.0014)$. According to these results, the reverse Trendelenburg or head elevated position resulted in lower subject IOP's. In contrast to these three studies, Grant et al. found that after being in the prone position for five hours, IOP in the horizontal position was $141 \%$ of baseline IOP compared to $178 \%$ of baseline IOP in the reverse Trendelenburg position.

There were several limitations that were encountered. Because of the small number of studies conducted on intraocular pressure (IOP) and prone positioning, only four studies met the criteria for inclusion in the systematic review. One of the goals of the systematic review was to include only randomized control trials; however, a pilot study was included in this review because of its relevance to the stated purpose. Therefore, the inclusion criteria was adjusted to include pilot studies.

The four studies each had different methods of evaluating head inclination and IOP. The studies each measured IOP at different intervals and during different head elevations (i.e. five, 10, and 30-degree reverse Trendelenburg and 10-degree head elevation), which limited the comparison between the trials. The inclusion and exclusion criteria between the studies were not identical, which may have resulted in different outcomes. The study by Grant et al. was a pilot study and the author did not indicate whether or not the subjects were randomized, which resulted in a lower level of 
evidence for this study compared to the other studies. However, because of the relevance of the study to this systematic review, the study by Grant et al. was included.

An additional limitation of this systematic review was that two of the studies included awake subjects (Ozcan et al. and Grant et al.), while the final two studies included anesthetized subjects undergoing surgery (Carey et al. and Emery et al.). Patients undergoing spine surgery under general anesthesia while in the prone position are at increased risk for POVL. Therefore, the randomized control trial by Carey et al. and Emery et al. were more indicative of intraocular pressure (IOP) changes in the clinical setting.

In conclusion, IOP was decreased in the reversed Trendelenburg or head elevated position in the majority of the studies, while IOP increased over time in the majority of the studies. This information allows health care professionals such as certified registered nurse anesthetists (CRNAs) to provide quality care for their patients by understanding the risks of spine surgery in the horizontal prone position over an extended period of time. Because POVL is so rare, it will be challenging to change the existing standard of care for patients undergoing spine surgery in the prone position. However, recommendations should be made and strategies for implementation identified to decrease the risk for POVL. 


\section{Recommendations and Implications for Advanced Nursing Practice}

By understanding that intraocular pressure (IOP) is attenuated by the reverse Trendelenburg or head elevated position and increased with longer duration of surgery, CRNAs have the potential to decrease patients' risk for developing the devastating complication of POVL through evidence-based changes in their practice. In each of the four studies included in this systematic review, a tonometer was used to measure the IOP of subjects at different intervals while in the prone position. The tonometer uses a small probe that applies soft pressure to the cornea of the eye, measuring the eye IOP. This author recommends use of the tonometer in anesthesia practice in order to measure IOP at different intervals during prone surgery. By using the tonometer in this way, the CRNA will be able to detect increased IOP and then elevate the head of the bed by placing the patient in reverse Trendelenburg position. The use of the tonometer by CRNAs is ideal; however there are limitations that must be considered. The tonometer is an expensive tool, and the price may vary from $\$ 1,000$ to $\$ 3,000$. Therefore, anesthesia providers may resist purchasing these devices since the risk of POVL is so low. Training in the use of the tonometer takes time and CRNAs would need to be amenable to this education process. Access to the patient's eyes for tonometer measurements is also a concern. If the patient is undergoing prone surgery in a foam headrest, the CRNA will not have access to the patient's eyes. However, if the patient's head is positioned in pins, the CRNA will have access to the eyes for tonometer measurements. The pin headrest is not used in every surgery by every surgeon, which limits the use of the 
tonometer in prone cases. Lastly, the tonometer includes a disposable latex tip, rendering it unfeasible in patients with latex allergy.

If tonometers are available in an institution, training programs for CRNAs and anesthesiologists must be implemented throughout the operating room. Required training should be completed with return demonstration either live or using simulation to demonstrate competence in the use of the tonometer. An ideal trainer would be an ophthalmologist skilled in the use of tonometers. Classes could be administered to demonstrate the use of the tonometer in the operating theater. After learning how to safely and effectively use the tonometer, a protocol should be developed that explains what interventions to take if the IOP is increased. A protocol may also be implemented in institutions where tonometers are not available. This protocol would provide instructions for CRNAs on how to decrease the risk for POVL, including placing the patient's head in a head-up or revere Trendelenburg position. With a protocol in place, the interventions would be more likely to be accepted by surgeons and operating room staff.

Because of the barriers to using the tonometer in the operating room, CRNAs are encouraged to take an educational approach by informing their patients about the risks of spine surgery in the prone position. Whether or not the CRNA has access to a tonometer, the CRNA must educate patients about the potential complications of spine surgery, including POVL, as they may not understand the risks involved. The preoperative period is an important time in which the patient should be assessed for 
increased risk of increased IOP and POVL. Even though the incidence of POVL is low, the patient should be aware that blindness is a possible complication while undergoing surgery in the prone position. The CRNA should also be able to explain to the patient that measures will be taken to prevent increased IOP, including possible tonometer measurements and use of the prone reverse Trendelenburg position.

The Anesthesia Patient Safety Foundation (APSF) developed an educational video for anesthesia providers in 2014 to discuss perioperative vision loss. Consensus was that the risk for POVL should be included in the informed consent process for anesthesia. The anesthesiologists found that after surveying patients, $80 \%$ of patients preferred full disclosure about the risks of POVL before the day of surgery. When malpractice claims are made for eye injury, a greater percentage of cases (10\%) are attributed to lack of informed consent prior to surgery compared to other surgical claims. This indicates that there is a lack of information about the risks of POVL in the preoperative informed consent process. It is recommended to provide informed consent to patients at high risk for POVL. This includes patients with a prior risk of ION or small cup or disk size. POVL should be explicitly described to the patient by the surgeon and anesthesiologist. The APSF recommends "During the informed consent process, anesthesia professionals and surgeons should include the remote risk of visual impairment, ranging from partial vision loss to complete blindness in both eyes" (APSF, 2014). 
The American Society of Anesthesiologists (ASA) Task Force on Perioperative Vision Loss detailed preoperative considerations for patients undergoing surgery in the prone position (2012). According to the ASA Task Force on Perioperative Vision Loss, patients at high risk for POVL include preoperative anemia, hypertension, diabetes, peripheral vascular disease, coronary artery disease, obesity, and tobacco use. Prolonged surgery (surgery greater than six and a half hours) and increased surgical blood loss (44.7\% of estimated blood loss) also increase the risk for POVL. The ASA Task Force on Perioperative Vision Loss suggests informing patients who plan to undergo prolonged procedures with predicted large amounts of blood loss. Recommendations for intraoperative management of the patient have also been recommended. It is recommended to maintain blood pressure within $24 \%$ of baseline mean arterial pressure, monitor central venous pressure in high-risk patients, administer colloids and crystalloids to maintain intravascular volume in patients with blood loss, monitor hemoglobin and hematocrit, maintain a hemoglobin above $9.4 \mathrm{~g} / \mathrm{dl}$ and hematocrit above $28 \%$, reduce pressure on the eye during surgery, and to maintain the high-risk patient's head level with or higher than the heart. By following these recommendations, the CRNA may decrease a patient's risk for developing POVL.

Another recommendation for anesthesia and surgical practice is to carry out spine surgery in a prone reverse Trendelenburg position. Emery et al. (2015) stated that slight head elevation is benign for most patients and adoption of head elevation during spine surgery could decrease the risk of POVL. Carey et al. (2013) concluded that reverse Trendelenburg patient positioning could be incorporated in operative spine cases as a 
preventative measure to diminish the occurrence of POVL. CRNAs should consider providing evidence-based education to the anesthesia department, surgeon and operating room staff. The goal would be to create a protocol for prone positioning during spine surgery. If a protocol were in place, the operating room staff would ensure that the patient would be positioned in a 10-degree reverse Trendelenburg position during the entire case, which would decrease the patient's risk for the development of POVL. By carrying out surgery in the 10-degree reverse Trendelenburg position, tonometer use may not be required due to the decreased risk of POVL in this position. Education about the benefits of the reverse Trendelenburg position during surgery in the prone position on IOP has the potential to improve patient outcomes. Operating rooms have weekly meetings and information about policy change may be discussed at one of these meetings after the information is presented. This would allow for feedback and questions to address staff concerns. The patient is the main priority for the entire operating room team. If the operating room staff were informed of the benefits of head elevation on IOP while in the prone position, then changing the patient position may be feasible.

Spreading knowledge to other CRNAs is very important in the education process. CRNAs have their own professional organizations, including the American Association of Nurse Anesthetists (AANA). Members of this organization meet once a year for the AANA Annual Congress meeting. Certified registered nurse anesthetists and student nurse anesthetists meet with other CRNAs from around the nation to spread education and knowledge about the anesthesia profession. Education about the importance of 
reverse Trendelenburg position during surgery in the prone position may be presented to the members of this organization as a power-point presentation or at a table with information displayed. Regional organizations for CRNAs include the Rhode Island Association for Nurse Anesthetists and the New England Assembly for Nurse Anesthetists. These organizations also meet a few times each year, and provide for a great opportunity for CRNAs to spread information and education about the risks of POVL during surgery in the prone position.

This author recommends further research on the benefits of reverse Trendelenburg position on IOP during surgery in the prone position. Only two of the four studies in this systematic review examined anesthetized subjects undergoing spine surgery in the prone position. Therefore, additional research on the effects of reverse Trendelenburg position and the use of a tonometer in this group population would allow for a more precise representation of patients in the clinical setting. Further research will help health care professionals understand the importance of the reverse Trendelenburg position during surgery in the prone position and allow CRNAs and anesthesiologists to decrease the patient's risk for POVL.

Postoperative vision loss is a very rare complication of spine surgery in the prone position. Even though it is rare, it can be detrimental to a patient, resulting in permanent blindness. As anesthesia providers, CRNAs must be vigilant while caring for patients in the prone horizontal position. By understanding that head elevation and use 
of the tonometer may decrease a patient's risk for POVL, the CRNA can provide the highest quality of care for their patients. 


\section{References}

Agah, M., Ghasemi, M., Roodneshin, F., Radpay, B., \& Siamak, M. (2011). Prone position in percutaneous nephrolithotomy and postoperative visual loss. Urology Journal, 8(3). 191-196.

American Society of Anesthesiologists Task Force on Perioperative Blindness (2006). Practice advisory for perioperative visual loss associated with spine surgery. Anesthesiology 2006, 104(6), 1319-1328. Retrieved from http://ftp.asahq.org/publicationsAndServices/BlindnessAdvisoryFinal.pdf

American Society of Anesthesiologists Task Force on Perioperative Blindness (2011).

Practice advisory for perioperative visual loss associated with spine surgery: An updated report by the American Society of Anesthesiologists Task Force on Perioperative Visual Loss. Anesthesiology 2012, 116(2), 274-285.

Anesthesia Patient Safety Foundation (2014). Perioperative vision loss (POVL): Risk factors and evolving management strategies. WWW.APSF.org. Retrieved from: http://www.apsf.org/resources/povl/watch

Carey, T. W., Shaw, K. A., Weber, M. L., \& DeVine, J. G. (2014). Effect of the degree of reverse trendelenburg position on intraocular pressure during prone spine surgery: a randomized controlled trial. Spine Journal, 14(9), 2118-2126 9p. doi:10.1016/j.spinee.2013.12.025

Chang, S. H. \& Miller, N., R. (2005). The incidence of vision loss due to perioperative ischemic optic neurpathy associated with spine surgery. Spine, 30, 1299-1302. Retrieved from http://www.medscape.com/viewarticle/506675 
Cheng, M. A., Todorov, A., Tempelhoff, R., McHugh, T., Crowder, C. M., \& Lauryssen, C. (2001). The effect of prone positioning on intraocular pressure in anesthetized patients. Anesthesiology 2001, 95, 1351-1355. Retrieved from http://anesthesiology.pubs.asahq.org/article.aspx?articleid=1944231

Critical Appraisal Skills Promgramme (CASP), (2017). Randomised controlled trials checklist 13.03.17. Retrieved from http://www.casp-uk.net/\#!casp-toolschecklists/c18f8

Effective Public Health Practice Project, (2009). Quality assessment tool for quantitative studies. Retrieved from: http://www.ephpp.ca/tools.html

Emery, S. E., Daffner, S. D., France, J. C., Ellison, M., Grose, B. W., Hobbs, G. R., \& Clovis, N. B. (2015). Effect of head position on intraocular pressure during lumbar spine fusion: A randomized, prospective study. Journal Of Bone \& Joint Surgery, American Volume, 97(22), 1817-1823 7p. doi:10.2106/JBJS.0.00091

Foster, M. J., \& Shurtz, S. (2013). Making the Critical Appraisal for Summaries of Evidence (CASE) for evidence-based medicine (EBM): critical appraisal of summaries of evidence. Journal of the Medical Library Association : JMLA, 101(3), 192-198. http://doi.org/10.3163/1536-5050.101.3.008

Grant, G. P., Szirth, B. C., Bennett, H. L., Huang, S. S., Thaker, R. S., Heary, R. F., \& Turbin, R. E. (2010). Effects of prone and reverse trendelenburg positioning on ocular parameters. Anesthesiology, 112(1), 57-65. doi:10.1097/ALN.0b013e3181c294e1 Hall, J.E. (2016). Guyton and Hall textbook of medical physiology (13 ${ }^{\text {th }}$ ed.). Philidelphia, PA: Elsevier Inc. 
Heitz, J.W., \& Audu, P.B. (2008). Asymmetric postoperative visual loss after spine surgery in the lateral decubitus position. British Journal of Anaethesia, 101, 380-382. Retrieved from http://bja.oxfordjournals.org/content/101/3/380.full.pdf+html

Holy, S.E., Tsai, J.H., McAllister, R.K., \& Smith, K.H. (2009). Perioperative ischemic optic neuropathy: a case control analysis of 126,666 surgical procedures at a single institution. Anesthesiology, 110, 246-253.

Kamel, I., \& Barnette, R., (2014). Positioning patients for spine surgery: Avoiding uncommon position-related complications. World Journal of Orthopedics, 5, 425443. doi:10.5312/wjo.v5.i4.425

Kitaba, A., Martin, D.P., Gopalakrishnan, S., \& Tobias, J.D. (2013). Perioperative vision loss after nonocular surgery. J Anesth, 27. 919-926.

Lee, L.A., Roth, S., Posner, K., Cheney, F.W., Caplan, R.A., Newman, N.J., \& Domino, K.B., (2006). The American Society of Anesthesiologists postoperative visual loss registry: Analysis of 93 spine surgery cases with postoperative visual loss. Anesthesiology 2006, 105(4), 652-659

Liberati, A., Altman, D.G., Tetzlaff, J., Mulrow, C., Gotzsche, P.C., Ioannidis, J.P.A., Clarke, M., Devereaux, P.J., Kleijnen, J., \& Moher, D., (2009). The PRISMA statement for reporting systematic reviews and meta-analyses of studies that evaluate health care interventions: Explanation and elaboration. PLoS Med 6, e1000100. doi:10.1371/journal.pmed.1000100. 
Moher D, Liberati A, Tetzlaff J, Altman DG, \& the PRISMA Group, (2009). Preferred reporting items for systematic reviews and meta-analyses: The PRISMA statement. Ann Intern Med., 151, 264-269. doi:10.7326/0003-4819-151-4200908180-00135

Moher, D., Shamseer, L., Clarke, M., Ghersi, D., Liberati, A., Petticrew, M., Sheckelle, P., Stewart, L.A., \& Prisma-P Group, (2015). Preferred reporting items for systematic review and meta-analysis protocols (PRISMA-P) 2015 statement. BioMed Central 4(1), 2-9. Doi: 10.1186/2046-4053-4-1

Molloy, B.L., (2011). Implications for postoperative vision loss: Steep trendelenburg position and effects on intraocular pressure. AANA Journal, 79(2). 115-121fara. Molloy, B., (2012). A preventative intervention for rising intraocular pressure: Development of the Molloy/Bridgeport anesthesia associates observation scale. AANA Journal, 80(3). 213-222.

Nickels, T.J., Manlapaz, M.R., \& Farag, E., (2014). Perioperative visual loss after spine surgery. World Journal of Orthopedics, 5(2), 100-106. doi: 10.5312/wjo.v5.i2.100 Ozcan, MS., Praetel, C., Bhatti, MT., Gravenstein, N., Mahla, ME., \& Seubert, CN. (2004). The effect of body inclination during prone positioning on intraocular pressure in awake volunteers: a comparison of two operating tables. Anesth Analg. 99:1152-8.

PPCRP, 2006. Description of levels of evidence, grades and recommendations. Practicing Chiropractors' Committee on Radiology Protocols. Retrieved from http://www.pccrp.org/docs/pccrp\%20section\%20i.pdf 
Roth, S., Thisted, R.A., Erickson, J.P., Black, S., \& Schreider, B.D., (1996). Eye injuries after nonocular surgery. Anesthesiology, 85:1020-7.

Shamseer, L., Moher, D., Clarke, M., Ghersi, D., Liberati, A., Petticrew, M., Shekelle, P., Stewart, L.A., \& the PRISMA-P Group, (2015). Preferred reporting items for systematic review and meta-analysis protocols (PRISMA-P) 2015: Elaboration and explanation. BMJ, 3-25, doi: 10.1136/bmj.g7647

The Postoperative Visual Loss Study Group (2012). Risk factors associated with ischemic optic neuropathy after spinal fusion surgery. Anesthesiology, 116, 15-24.

Walick, K., Kragh JE, J., Ward, J., \& Crawford, J. (2007). Changes in intraocular pressure due to surgical positioning: studying potential risk for postoperative vision loss. Spine (03622436), 32(23), 2591-2595 5p.

Yoshimura, K., Hayashi, H., Tanaka, Y., Nomura, Y., \& Kawaguchi, M., (2015). Evaluation of predictive factors associated with increased intraocular pressure during prone position spine surgery. J Anesth, 29, 170-174. Doi: 10.1007/s00540-014-1921-8 


\section{Appendix A}

\section{Table 1. Checklist of Items to Include When Reporting a Systematic Review or Meta-Analysis}

\begin{tabular}{|c|c|c|c|}
\hline Section/Topic & $\begin{array}{l}\text { Item } \\
\#\end{array}$ & Checklist Item & $\begin{array}{l}\text { Reported on } \\
\text { Page \# }\end{array}$ \\
\hline \multicolumn{4}{|l|}{ TITLE } \\
\hline Title & 1 & Identify the report as a systematic review, meta-analysis, or both. & \\
\hline \multicolumn{4}{|l|}{ ABSTRACT } \\
\hline Structured summary & 2 & $\begin{array}{l}\text { Provide a structured summary including, as applicable: background; objectives; data sources; study } \\
\text { eligibility criteria, participants, and interventions; study appraisal and synthesis methods; results; } \\
\text { limitations; conclusions and implications of key findings; systematic review registration number. }\end{array}$ & \\
\hline \multicolumn{4}{|l|}{ INTRODUCTION } \\
\hline Rationale & 3 & Describe the rationale for the review in the context of what is already known. & \\
\hline Objectives & 4 & $\begin{array}{l}\text { Provide an explicit statement of questions being addressed with reference to participants, } \\
\text { interventions, comparisons, outcomes, and study design (PICOS). }\end{array}$ & \\
\hline \multicolumn{4}{|l|}{ METHODS } \\
\hline Protocol and registration & 5 & $\begin{array}{l}\text { Indicate if a review protocol exists, if and where it can be accessed (e.g., Web address), and, if } \\
\text { available, provide registration information including registration number. }\end{array}$ & \\
\hline Eligibility criteria & 6 & $\begin{array}{l}\text { Specify study characteristics (e.g., PICOS, length of follow-up) and report characteristics (e.g., } \\
\text { years considered, language, publication status) used as criteria for eligibility, giving rationale. }\end{array}$ & \\
\hline Information sources & 7 & $\begin{array}{l}\text { Describe all information sources (e.g., databases with dates of coverage, contact with study } \\
\text { authors to identify additional studies) in the search and date last searched. }\end{array}$ & \\
\hline Search & 8 & $\begin{array}{l}\text { Present full electronic search strategy for at least one database, including any limits used, such } \\
\text { that it could be repeated. }\end{array}$ & \\
\hline Study selection & 9 & $\begin{array}{l}\text { State the process for selecting studies (i.e., screening, eligibility, included in systematic review, } \\
\text { and, if applicable, included in the meta-analysis). }\end{array}$ & \\
\hline Data collection process & 10 & $\begin{array}{l}\text { Describe method of data extraction from reports (e.g., piloted forms, independently, in duplicate) } \\
\text { and any processes for obtaining and confirming data from investigators. }\end{array}$ & \\
\hline Data items & 11 & $\begin{array}{l}\text { List and define all variables for which data were sought (e.g., PICOS, funding sources) and any } \\
\text { assumptions and simplifications made. }\end{array}$ & \\
\hline $\begin{array}{l}\text { Risk of bias in individual } \\
\text { studies }\end{array}$ & 12 & $\begin{array}{l}\text { Describe methods used for assessing risk of bias of individual studies (including specification of } \\
\text { whether this was done at the study or outcome level), and how this information is to be used } \\
\text { in any data synthesis. }\end{array}$ & \\
\hline Summary measures & 13 & State the principal summary measures (e.g., risk ratio, difference in means). & \\
\hline Synthesis of results & 14 & $\begin{array}{l}\text { Describe the methods of handling data and combining results of studies, if done, including } \\
\text { measures of consistency }\left(\text { e.g., } 1^{2}\right) \text { for each meta-analysis. }\end{array}$ & \\
\hline $\begin{array}{l}\text { Risk of bias across } \\
\text { studies }\end{array}$ & 15 & $\begin{array}{l}\text { Specify any assessment of risk of bias that may affect the cumulative evidence (e.g., publication } \\
\text { bias, selective reporting within studies). }\end{array}$ & \\
\hline Additional analyses & 16 & $\begin{array}{l}\text { Describe methods of additional analyses (e.g., sensitivity or subgroup analyses, meta-regression), if } \\
\text { done, indicating which were pre-specified. }\end{array}$ & \\
\hline \multicolumn{4}{|c|}{ : } \\
\hline Study selection & 17 & $\begin{array}{l}\text { Give numbers of studies screened, assessed for eligibility, and included in the review, with reasons } \\
\text { for exclusions at each stage, ideally with a flow diagram. }\end{array}$ & \\
\hline Study characteristics & 18 & $\begin{array}{l}\text { For each study, present characteristics for which data were extracted (e.g., study size, PICOS, } \\
\text { follow-up period) and provide the citations. }\end{array}$ & \\
\hline $\begin{array}{l}\text { Risk of bias within } \\
\text { studies }\end{array}$ & 19 & $\begin{array}{l}\text { Present data on risk of bias of each study and, if available, any outcome-level assessment (see } \\
\text { Item 12). }\end{array}$ & \\
\hline $\begin{array}{l}\text { Results of individual } \\
\text { studies }\end{array}$ & 20 & $\begin{array}{l}\text { For all outcomes considered (benefits or harms), present, for each study: (a) simple summary data } \\
\text { for each intervention group and (b) effect estimates and confidence intervals, ideally with a } \\
\text { forest plot. }\end{array}$ & \\
\hline Synthesis of results & 21 & $\begin{array}{l}\text { Present results of each meta-analysis done, including confidence intervals and measures of } \\
\text { consistency. }\end{array}$ & \\
\hline $\begin{array}{l}\text { Risk of bias across } \\
\text { studies }\end{array}$ & 22 & Present results of any assessment of risk of bias across studies (see Item 15). & \\
\hline Additional analysis & 23 & $\begin{array}{l}\text { Give results of additional analyses, if done (e.g., sensitivity or subgroup analyses, meta-regression } \\
\text { [see Item 16]). }\end{array}$ & \\
\hline \multicolumn{4}{|l|}{ DISCUSSION } \\
\hline Summary of evidence & 24 & $\begin{array}{l}\text { Summarize the main findings including the strength of evidence for each main outcome; consider } \\
\text { their relevance to key groups (e.g., health care providers, users, and policy makers). }\end{array}$ & \\
\hline Limitations & 25 & $\begin{array}{l}\text { Discuss limitations at study and outcome level (e.g., risk of bias), and at review level (e.g., } \\
\text { incomplete retrieval of identified research, reporting bias). }\end{array}$ & \\
\hline Conclusions & 26 & $\begin{array}{l}\text { Provide a general interpretation of the results in the context of other evidence, and implications } \\
\text { for future research. }\end{array}$ & \\
\hline \multicolumn{4}{|l|}{ FUNDING } \\
\hline Funding & 27 & $\begin{array}{l}\text { Describe sources of funding for the systematic review and other support (e.g., supply of data); } \\
\text { role of funders for the systematic review. }\end{array}$ & \\
\hline
\end{tabular}




\section{Appendix B}

"Did the trial address a clearly focused issue?"

"Was the assignment of patients to treatments randomized?"

"Were all of the patients who entered the trial properly accounted for at its conclusion?"

“Were patients, health workers and study personnel 'blind' to treatment?

"Were the groups similar at the start of the trial?"

“Aside from the experimental intervention, were the groups treated equally?"

"Were all the patients who entered the trial properly accounted for at its conclusion?"

"How large was the treatment effect?"

"How precise was the estimate of the treatment effect?"

"Can the results be applied in your context?"

"Were all clinically important outcomes considered?"

"Are the benefits worth the harms and costs?"

(CASP, 2017) 


\section{Appendix C1}

\section{Data Collection Tool 1}

Ozcan, M.S., Praetel, C., Bhatti, M.T., Gravenstein, N., Mahla, M.E., Seubert, C.N. (2004). The effect of body inclination during prone positioning on intraocular pressure in awake volunteers: A comparison of two operating tables. Anesth Analg. 99:1152-8.

\begin{tabular}{|c|c|c|c|c|c|c|}
\hline Purpose & Study Design & $\begin{array}{l}\text { Sample and subject } \\
\text { demographics }\end{array}$ & Method & $\begin{array}{l}\text { Positions } \\
\text { compared }\end{array}$ & Measurement & Data analysis \\
\hline $\begin{array}{l}\text { The aim of this } \\
\text { study was to } \\
\text { determine whether } \\
\text { or not the reverse } \\
\text { Trendelenburg } \\
\text { position } \\
\text { ameliorates the } \\
\text { increase in IOP } \\
\text { caused by prone } \\
\text { positioning }\end{array}$ & $\begin{array}{l}\text { Randomized } \\
\text { crossover study. } \\
\text { Inclusion criteria: } \\
\text { ASA I or II } \\
\text { Exclusion criteria: } \\
\text { body mass index } \\
\text { greater than } \\
30 \mathrm{~kg} / \mathrm{m}^{2} \text {. Medical } \\
\text { therapy with } \beta \text { - } \\
\text { adrenergic } \\
\text { blockers, } \\
\text { cholinesterase } \\
\text { inhibitors, or } \\
\text { muscarinic } \\
\text { agonists. Allergy to } \\
\text { proparacaine or } \\
\text { latex. Preexisting } \\
\text { eye disorder except } \\
\text { for refractice errors } \\
\text { within } \pm \text { diopters }\end{array}$ & $\begin{array}{l}10 \text { awake subjects } \\
\text { age: } 30.2 \pm 8.0 \\
\text { sex }(\mathrm{M} / \mathrm{F}): 7 / 3 \\
\text { height }(\mathrm{cm}): 172.6 \pm \\
7.3 \\
\text { weight }(\mathrm{kg}): 71.4 \pm \\
10.8 \\
\text { BMI range }\left(\mathrm{kg} / \mathrm{m}^{2}\right) \text { : } \\
22.1-27.8\end{array}$ & $\begin{array}{l}\text { There were } 2 \\
\text { separate } 25 \text {-minute } \\
\text { sessions, at least } \\
\text { one week apart, for } \\
\text { each subject. In the } \\
\text { first setting, the } \\
\text { subject was on a } \\
\text { Jackson table, and } \\
\text { in the second } \\
\text { setting, the subject } \\
\text { was on a Wilson } \\
\text { frame. }\end{array}$ & $\begin{array}{l}\text { Sitting upright } \\
\text { (sitting), supine on } \\
\text { a horizontal OR } \\
\text { table (supine), } \\
\text { prone on a } \\
\text { horizontal OR table } \\
\text { (prone-horizontal } \\
\text { 1), prone with a } 10^{\circ} \\
\text { reverse } \\
\text { Trendelenburg } \\
\text { position (prone- } \\
\text { head up), prone } \\
\text { with a } 10^{\circ} \\
\text { Trendelenburg } \\
\text { position (prone- } \\
\text { head down), and } \\
\text { prone with the } \\
\text { table back to } \\
\text { hosizontal (prone- } \\
\text { horizontal 2). }\end{array}$ & $\begin{array}{l}\text { IOP was checked in } \\
\text { both eyes in six } \\
\text { different positions } \\
\text { by applanation } \\
\text { tonometry with the } \\
\text { handheld Tono-Pen } \\
\text { XL. IOP was } \\
\text { measured } 5 \\
\text { minutes after each } \\
\text { position change. }\end{array}$ & $\begin{array}{l}\text { Data was analyzed } \\
\text { with two-way } \\
\text { repeated measures } \\
\text { analysis of variance, } \\
\text { followed by Tukey } \\
\text { post hoc testing. A } \\
P<0.05 \text { indicated a } \\
\text { statistically } \\
\text { significant } \\
\text { difference. }\end{array}$ \\
\hline
\end{tabular}


Appendix C2

\section{Data Collection Tool 1}

Grant, G. P., Szirth, B. C., Bennett, H. L., Huang, S. S., Thaker, R. S., Heary, R. F., \& Turbin, R. E. (2010). Effects of prone and reverse trendelenburg positioning on ocular parameters. Anesthesiology, 112(1), 57-65.

\begin{tabular}{|c|c|c|c|c|c|c|}
\hline Purpose & Study Design & $\begin{array}{l}\text { Sample and } \\
\text { subject } \\
\text { demographics }\end{array}$ & Method & Positions compared & Measurement & Data analysis \\
\hline $\begin{array}{l}\text { The purpose of } \\
\text { this study was to } \\
\text { evaluate the } \\
\text { effect of prone } \\
\text { position and a 4- } \\
\text { degree increase } \\
\text { in table incline } \\
\text { over a } 5 \text { hour } \\
\text { period on IOP as } \\
\text { well as } \\
\text { ultrasound } \\
\text { imaging of the } \\
\text { choroid layer } \\
\text { and optic nerve } \\
\text { diameter in a } \\
\text { larger sample } \\
\text { size of awake } \\
\text { subjects }\end{array}$ & $\begin{array}{l}\text { A pilot study of } \\
\text { awake subjects. } \\
\text { Exclusion } \\
\text { criteria: allergy } \\
\text { to proparacaine } \\
\text { or tropicamide, } \\
\text { preexisting eye } \\
\text { disease or eye } \\
\text { surgery, the } \\
\text { inability to lie } \\
\text { prone for } 5 \mathrm{~h} \text {. }\end{array}$ & $\begin{array}{l}10 \text { subjects, } \\
\text { ASA physical } \\
\text { status I-II, age } \\
\text { 23-60. Sex M/F: } \\
\text { 5/5. Weight: } \\
\text { 56-147kg } \\
\text { BMI: } 21.3-37.6 \\
\mathrm{~kg} / \mathrm{m}^{2}\end{array}$ & $\begin{array}{l}\text { There were two } \\
\text { separate sessions for } \\
\text { each subject. In the } \\
\text { first session, baseline } \\
\text { IOP was measured } \\
\text { on a horizontal table } \\
\text { at nine different } \\
\text { intervals. In the } \\
\text { second session, } \\
\text { identical } \\
\text { measurements were } \\
\text { taken with the } \\
\text { patient in a 4-degree } \\
\text { reverse } \\
\text { Trendelenburg } \\
\text { position. }\end{array}$ & $\begin{array}{l}\text { Supine position, } \\
\text { after immediate } \\
\text { prone positioning } \\
\text { (prone 0), hourly for } \\
5 \text { hours in the prone } \\
\text { position (prone 1-5), } \\
\text { and immediately on } \\
\text { return to the supine } \\
\text { position (post 0), } \\
\text { and after } 30 \text { minutes } \\
\text { in the supine 30- } \\
\text { degree reverse } \\
\text { Trendelenburg } \\
\text { position (post } 30 \text { ) }\end{array}$ & $\begin{array}{l}\text { IOP was measured in } \\
\text { the right eye using the } \\
\text { Tono-pen XL } \\
\text { applanation tonometer. } \\
\text { Local anesthetic was } \\
\text { administered to the } \\
\text { eye, and a soft contact } \\
\text { lens was inserted to } \\
\text { prevent corneal } \\
\text { abrasion from repeated } \\
\text { measures of IOP. } \\
\text { Ultrasound imaging of } \\
\text { the left eye was } \\
\text { performed through a } \\
\text { closed eyelid using the } \\
\text { Sonomed B-1000. } \\
\text { Choroid thickness, } \\
\text { retrobulbar optic nerve } \\
\text { diameter, visual acuity, } \\
\text { blood pressure, heart } \\
\text { rate, and oxygen }\end{array}$ & $\begin{array}{l}\text { Measurements were } \\
\text { calculated as a percent } \\
\text { of baseline (supine). } \\
\text { The effects of table } \\
\text { position and time } \\
\text { were evaluated using } \\
\text { ANOVA.Post } 0 \text { and } \\
\text { post } 30 \text { were } \\
\text { compared with } \\
\text { baseline using ANOVA, } \\
\text { post hoc analysis. Data } \\
\text { were reported as } \\
\text { mean } \pm \text { SD and } \\
\text { analyzed using the } \\
\text { SPSS system. } P<0.05 \\
\text { was considered } \\
\text { significant. }\end{array}$ \\
\hline
\end{tabular}




\begin{tabular}{|l|l|l|l|l|l|l|}
\hline & & & & $\begin{array}{l}\text { saturation were also } \\
\text { measured. }\end{array}$ & \\
\hline
\end{tabular}

Appendix C3

\section{Data Collection Tool 1}

Carey, T. W., Shaw, K. A., Weber, M. L., \& DeVine, J. G. (2014). Effect of the degree of reverse trendelenburg position on intraocular pressure during prone spine surgery: a randomized controlled trial. Spine Journal, 14(9), 2118-2126 9p.

\begin{tabular}{|c|c|c|c|c|c|c|}
\hline Purpose & Study Design & $\begin{array}{l}\text { Sample and subject } \\
\text { demographics }\end{array}$ & Method & $\begin{array}{l}\text { Positions } \\
\text { compared }\end{array}$ & Measurement & Data analysis \\
\hline $\begin{array}{l}\text { The purpose of this } \\
\text { study was to } \\
\text { investigate the } \\
\text { effect that patient } \\
\text { positioning exerted } \\
\text { on IOP during } \\
\text { prone spine } \\
\text { surgery. }\end{array}$ & $\begin{array}{l}\text { Single-center, } \\
\text { prospective } \\
\text { randomized control } \\
\text { study. } \\
\text { Inclusion criteria: } \\
\text { subjects with no } \\
\text { preexisting eye } \\
\text { pathology, history } \\
\text { of ophthalmic } \\
\text { surgery, allergy to } \\
\text { latex, or } \\
\text { hypersensitivity to } \\
\text { topical ester } \\
\text { anesthetics. }\end{array}$ & $\begin{array}{l}21 \text { subjects of the } \\
\text { Dwight } D \text {. } \\
\text { Eisenhower Army } \\
\text { Medical Center } \\
\text { Spine Clinic } \\
\text { preparing to } \\
\text { undergo spine } \\
\text { surgery. }\end{array}$ & $\begin{array}{l}\text { During their } \\
\text { preoperative } \\
\text { assessment, the } \\
\text { subjects were } \\
\text { randomized into } \\
\text { one of three table } \\
\text { positions: neutral, } \\
\text { 5, or } 10 \text { degree } \\
\text { reverse } \\
\text { Trendelenburg. IOP } \\
\text { was measured at } 5 \\
\text { different intervals }\end{array}$ & $\begin{array}{l}\text { Prone on a flat } \\
\text { table with } 0^{\circ} \\
\text { incline, prone with } \\
5^{\circ} \text { incline, prone } \\
\text { with } 10^{\circ} \text { incline. } \\
\text { The subjects were } \\
\text { all placed on a } \\
\text { Jackson Spine table } \\
\text { with the Mayfield } \\
\text { head attachment. } \\
\text { IOP was measured } \\
\text { preinduction, } 30 \\
\text { minutes after } \\
\text { induction in supine } \\
\text { position, } 30 \text { and } 60 \\
\text { minutes after prone } \\
\text { position, and every } \\
\text { hour thereafter. }\end{array}$ & $\begin{array}{l}\text { IOP was measured } \\
\text { in each eye by } \\
\text { Certified registered } \\
\text { nurse anesthetists } \\
\text { using a Tono-pen } \\
\text { XL. The subject's } \\
\text { eyes were } \\
\text { anesthetized using } \\
\text { topical anesthetic } \\
\text { for preinduction } \\
\text { measurement only. } \\
\text { MAP, estimated } \\
\text { blood loss, and fluid } \\
\text { resuscitation were } \\
\text { also measured. }\end{array}$ & $\begin{array}{l}\text { The continuous } \\
\text { variable of mean } \\
\text { IOP of each eye was } \\
\text { assessed for } \\
\text { treatment group } \\
\text { differences using a } \\
\text { two-way analysis of } \\
\text { variance (ANOVA) } \\
\text { with degree of } \\
\text { inclination as a } \\
\text { between-subject } \\
\text { variable and time } \\
\text { as a within-subject } \\
\text { variable. Significant } \\
\text { differences for } \\
\text { angle of inclination } \\
\text { at each time } \\
\text { interval were } \\
\text { examined using a } \\
\text { Scheffe correction }\end{array}$ \\
\hline
\end{tabular}




\begin{tabular}{|l|l|l|l|l|l|l|}
\hline & & & & & $\begin{array}{l}\text { for multiple } \\
\text { comparisons }\end{array}$ \\
\hline
\end{tabular}

Appendix C4

\section{Data Collection Tool 1}

Emery, S. E., Daffner, S. D., France, J. C., Ellison, M., Grose, B. W., Hobbs, G. R., \& Clovis, N. B. (2015). Effect of head position on intraocular pressure during lumbar spine fusion: A randomized, prospective study. Journal Of Bone \& Joint Surgery, American Volume, 97(22), 1817-1823

\begin{tabular}{|c|c|c|c|c|c|c|}
\hline Purpose & Study Design & $\begin{array}{l}\text { Sample and subject } \\
\text { demographics }\end{array}$ & Method & $\begin{array}{l}\text { Positions } \\
\text { compared }\end{array}$ & Measurement & Data analysis \\
\hline $\begin{array}{l}\text { The purpose of } \\
\text { this study was } \\
\text { to measure the } \\
\text { effect of } 10^{\circ} \text { of } \\
\text { head elevation } \\
\text { on IOP in a } \\
\text { patient } \\
\text { population } \\
\text { undergoing } \\
\text { lumbar fusion } \\
\text { and to identify } \\
\text { intraoperative } \\
\text { factors that } \\
\text { could affect IOP } \\
\text { over several } \\
\text { hours of } \\
\text { surgery. }\end{array}$ & $\begin{array}{l}\text { Randomized, } \\
\text { prospective trial } \\
\text { Inclusion criteria: } \\
\text { lumbar spine fusion, } \\
\text { age of } 18-80 \text { years } \\
\text { Exclusion criteria: } \\
\text { diagnosis of tumor, } \\
\text { infection, traumatic } \\
\text { injury, or a history of } \\
\text { eye disease, ocular } \\
\text { surgery, cervical } \\
\text { spine surgery, } \\
\text { chronic neck pain, or } \\
\text { cervical stenosis }\end{array}$ & $\begin{array}{l}63 \text { subjects. } \\
\text { Group I included } 33 \\
\text { subjects. Group II } \\
\text { included } 30 \text { subjects. Six } \\
\text { subjects were dropped } \\
\text { from the study due to } \\
\text { various circumstances. } \\
\text { Group I } \\
\text { Age: } 57.6 \pm 13.6 \\
\text { Sex M/F: } 18 / 9 \\
\text { No. of levels fused: } 1.4 \pm \\
0.6 \\
\text { Duration of procedure: } \\
270.2 \pm 105.5 \\
\text { ASA classification: } 2.5 \pm \\
0.6 \\
\text { Group II } \\
\text { Age: } 54.6 \pm 11.4 \\
\text { Sex M/F: } 17 / 8 \\
\text { No. levels fused: } 1.6 \pm 0.8\end{array}$ & $\begin{array}{l}\text { The subjects were } \\
\text { randomized into one } \\
\text { of two groups. The } \\
\text { subjects were blinded } \\
\text { to their assigned } \\
\text { group before and } \\
\text { after surgery. IOP } \\
\text { was measured while } \\
\text { sitting in the } \\
\text { preoperative area, } \\
\text { following induction of } \\
\text { anesthesia while } \\
\text { supine, } 5 \text { minutes } \\
\text { after positioned } \\
\text { prone, and every } 15 \\
\text { minutes during the } \\
\text { operation until } 3 \\
\text { readings in a row } \\
\text { were within } 3 \mathrm{mmHg} \\
\text { of each other. An }\end{array}$ & $\begin{array}{l}\text { Group I: head } \\
\text { remained in a } \\
\text { neutral position, } \\
\text { prone } \\
\text { Group II: head was } \\
\text { elevated } 10^{\circ} \text { in } \\
\text { relation to the } \\
\text { horizontal plane of } \\
\text { the level table. } \\
\text { Gardner-Wells tong } \\
\text { traction with 10lb } \\
\text { of weight was used } \\
\text { for head } \\
\text { positioning, and the } \\
\text { traction was } \\
\text { adjusted for } \\
\text { subjects in group II } \\
\text { to elevated the } \\
\text { head } 10^{\circ} \text { from } \\
\text { horizontal. The }\end{array}$ & $\begin{array}{l}\text { IOP was } \\
\text { measured, in } \\
\text { all subjects, by } \\
\text { the same } \\
\text { research } \\
\text { technician. } \\
\text { Measurements } \\
\text { were obtained } \\
\text { with an } \\
\text { applanation } \\
\text { tonometer. }\end{array}$ & $\begin{array}{l}\text { Data was analyzed } \\
\text { using ANCOVA. } \\
\text { The change in the } \\
\text { two-eye average } \\
\text { of IOP was the } \\
\text { single outcome } \\
\text { determining } f \text { the } \\
\text { trial would be } \\
\text { positive or } \\
\text { negative. } \\
\text { Descriptive } \\
\text { statistical analyses } \\
\text { included the } \\
\text { mean, standard } \\
\text { deviation, and } \\
\text { range for the IOPs } \\
\text { measured at each } \\
\text { of the time points } \\
\text { in the control and }\end{array}$ \\
\hline
\end{tabular}




\begin{tabular}{|l|l|l|l|l|l|l|}
\hline & Duration of procedure: & hour later, & table remained & & intervention \\
measurements were & $\begin{array}{l}\text { parallel to the floor } \\
\text { in all cases. }\end{array}$ & & groups \\
& & ASA classification: $2.4 \pm$ & taken again & & \\
& & & & & \\
\hline
\end{tabular}

Appendix D1

\section{Data Collection Tool 2}

Ozcan, M.S., Praetel, C., Bhatti, M.T., Gravenstein, N., Mahla, M.E., Seubert, C.N. (2004). The effect of body inclination during prone positioning on intraocular pressure in awake volunteers: A comparison of two operating tables. Anesth Analg. 99:1152-8.

\begin{tabular}{|c|c|c|c|c|}
\hline Baseline IOP & $\begin{array}{l}\text { Variables/ Outcomes } \\
\text { examined }\end{array}$ & $\begin{array}{l}\text { IOP measurements } \\
\text { in each interval }\end{array}$ & $\begin{array}{l}\text { Findings } \\
\text { Prone / Reverse Trendelenburg }\end{array}$ & Limitations \\
\hline $\begin{array}{l}\text { Sitting position: } 15.0 \\
\mathrm{~mm} \mathrm{Hg} \text { (12.8-16.3 } \\
\mathrm{mm} \mathrm{Hg} \text { ) (median } \\
25^{\text {th }}-75^{\text {th }} \text { percentile) } \\
\text { Supine position: } \\
16.8 \mathrm{~mm} \mathrm{Hg}(14.0- \\
18.3 \mathrm{~mm} \mathrm{Hg})\end{array}$ & $\begin{array}{l}\text { IOP was strongly affected } \\
\text { by body position on the OR } \\
\text { table } \\
\text { The choice of table (Jackson } \\
\text { table or Wilson frame) was } \\
\text { not statistically different in } \\
\text { the measurement of IOP. } \\
\text { The effect of heart rate was } \\
\text { statistically but not } \\
\text { clinically significant. }\end{array}$ & $\begin{array}{l}\text { Prone horizontal: } \\
22.5 \mathrm{~mm} \mathrm{Hg}(19.8- \\
25.3 \mathrm{~mm} \mathrm{Hg} \text { ) } \\
\text { Trendelenburg: } 23.8 \\
\mathrm{~mm} \mathrm{Hg}(21.5-26.3 \\
\mathrm{mm} \mathrm{Hg}) \\
\text { Reverse } \\
\text { Trendelenburg: } 20.3 \\
\mathrm{~mm} \mathrm{Hg} \text { (16.3-22.5 } \\
\mathrm{mm} \mathrm{Hg})\end{array}$ & $\begin{array}{l}\text { Both body position and OR table } \\
\text { inclination profoundly influenced the IOP } \\
\text { in awake subjects. } \\
\text { The reverse Trendelenburg position } \\
\text { ameliorated the increase in IOP caused by } \\
\text { prone positioning but did not completely } \\
\text { normalize it. } \\
\text { The reverse Trendelenburg position } \\
\text { decreased the number of grossly } \\
\text { abnormal IOP values by } 50 \% \text { compared } \\
\text { with the prone horizontal position and by } \\
75 \% \text { compared with the Trendelenburg } \\
\text { position }\end{array}$ & $\begin{array}{l}\text { IOP was measured in awake } \\
\text { subjects compared to } \\
\text { anesthetized subjects. Therefore } \\
\text { IOP changes do not reflect IOp } \\
\text { changes under general } \\
\text { anesthesia. } \\
\text { The time spent in each position } \\
\text { was } 5 \text { minutes, which may not } \\
\text { reflect the actual time spent in } \\
\text { the positions during surgery. } \\
\text { No IV fluids were administered. } \\
\text { IV fluids may further exacerbate } \\
\text { increases in IOP in the prone } \\
\text { position by increasing venous } \\
\text { ocular pressure }\end{array}$ \\
\hline
\end{tabular}




\section{Appendix D2}

\section{Data Collection Tool 2}

Grant, G. P., Szirth, B. C., Bennett, H. L., Huang, S. S., Thaker, R. S., Heary, R. F., \& Turbin, R. E. (2010). Effects of prone and reverse trendelenburg positioning on ocular parameters. Anesthesiology, 112(1), 57-65.

\begin{tabular}{|c|c|c|c|c|}
\hline Baseline IOP & $\begin{array}{l}\text { Variables/ Outcomes } \\
\text { examined }\end{array}$ & $\begin{array}{l}\text { IOP measurements } \\
\text { in each interval }\end{array}$ & $\begin{array}{l}\text { Findings } \\
\text { Prone / Reverse Trendelenburg }\end{array}$ & Limitations \\
\hline $\begin{array}{l}\text { Supine position on } \\
\text { horizontal table: } 16 \\
\pm 3 \mathrm{SD} \text { mmHg } \\
\text { Supine position in } \\
\text { reverse } \\
\text { Trendelenburg: } 17 \\
\pm 4 \text { SD mmHg }\end{array}$ & $\begin{array}{l}\text { There was no significant } \\
\text { change with prone time or } \\
\text { effect of table inclination on } \\
\text { MAP or heart rate. There } \\
\text { was a significant effect of } \\
\text { time on the increase in IOP } \\
\text { in the prone position. }\end{array}$ & $\begin{array}{l}\text { The following results } \\
\text { are displayed as a } \\
\text { percentage of } \\
\text { baseline supine. } \\
\text { (Horizontal } \\
\text { table/Reverse } \\
\text { Trendelenburg) } \\
\text { Supine: } 100 \% / 100 \% \\
\text { Prone 0: } 120 \% / 127 \% \\
\text { Prone 1: } 136 \% / 149 \% \\
\text { Prone 2: } 135 \% / 163 \% \\
\text { Prone 3: } 154 \% / 175 \% \\
\text { Prone 4: } 148 \% / 162 \% \\
\text { Prone 5: } 141 \% / 178 \% \\
\text { Post 0: } 129 \% / 152 \% \\
\text { Post 30: } 100 \% / 119 \%\end{array}$ & $\begin{array}{l}\text { IOP, optic nerve diameter and } \\
\text { choroid thickness increased over a } \\
5 \text {-hour period in the prone } \\
\text { position. Table elevation of } 4- \\
\text { degrees only attenuated the } \\
\text { increase in choroid thickness ( } P \\
<0.05 \text { ). } \\
\text { There was a significant effect of } \\
\text { time on the increase in IOP in the } \\
\text { prone position ( } P<0.05 \text { ). There } \\
\text { was a greater increase in IOP in the } \\
\text { reverse Trendelenburg position } \\
\text { compared to the horizontal table } \\
\text { position. }\end{array}$ & $\begin{array}{l}\text { In patients } 2-10 \text {, each prone session was } \\
\text { followed by a rest period of } 30 \text { minutes } \\
\text { in the } 30 \text {-degree reverse Trendelenburg } \\
\text { position. } \\
\text { Using awake subjects does not provide } \\
\text { surgical controls. The baseline supine } \\
\text { measurements for optic nerve diameter } \\
\text { were higher than those published in } \\
\text { other studies, and baselines were } \\
\text { different for the two study sessions ( } 5.5 \\
\text { and } 6.2 \mathrm{~mm} \text {, respectively) }\end{array}$ \\
\hline
\end{tabular}




\section{Appendix D3}

\section{Data Collection Tool 2}

Carey, T. W., Shaw, K. A., Weber, M. L., \& DeVine, J. G. (2014). Effect of the degree of reverse trendelenburg position on intraocular pressure during prone spine surgery: a randomized controlled trial. Spine Journal, 14(9), 2118-2126 9p. 
Appendix D4

\begin{tabular}{|c|c|c|c|c|}
\hline Baseline IOP & Variables/ Outcomes examined & $\begin{array}{l}\text { IOP } \\
\text { measurements } \\
\text { in each interval }\end{array}$ & $\begin{array}{l}\text { Findings } \\
\text { Prone / Reverse Trendelenburg }\end{array}$ & Limitations \\
\hline $\begin{array}{l}\text { IOP in the } \\
\text { supine } \\
\text { position prior } \\
\text { to induction in } \\
\text { each position } \\
\text { Neutral: } \\
17.64 \pm 4.43 \\
\mathrm{SD} \mathrm{mmHg} \\
5^{\circ}: 19.33 \pm \\
4.56 \mathrm{SD} \mathrm{mmHg} \\
10^{\circ}: 17.75 \pm \\
2.38 \mathrm{SD} \mathrm{mmHg}\end{array}$ & $\begin{array}{l}57.14 \% \text { of subjects in the } \\
\text { neutral group experienced at } \\
\text { least one measurement of IOP } \\
\text { above } 30 \mathrm{mmHg} \text {. No subjects in } \\
5^{\circ} \text { or } 10^{\circ} \text { reverse Trendelenburg } \\
\text { experienced IOP above } 30 \\
\text { mmHg.. } \\
\text { There were no statistically } \\
\text { significant differences among } \\
\text { MAP and blood volume in the } \\
\text { three inclination groups. }\end{array}$ & $\begin{array}{l}\text { Preinduction } \\
\text { Neutral: } 17.64 \\
5^{\circ}: 19.33 \\
10^{\circ}: 17.75 \\
\text { Postinduction } \\
\text { Neutral: } 15.29 \\
5^{\circ}: 15.67 \\
10^{\circ}: 14.00 \\
30 \text { min prone } \\
\text { Neutral: } 24.93 \\
5^{\circ}: 22.08 \\
10^{\circ}: 20.50 \\
60 \text { min prone } \\
\text { Neutral: } 26.33 \\
5^{\circ}: 23.17 \\
10^{\circ}: 21.42 \\
120 \text { min prone } \\
\text { Neutral: } 26.13 \\
5^{\circ}: 25.08 \\
10^{\circ}: 21.88\end{array}$ & $\begin{array}{l}\text { Reverse Trendelenburg position } \\
\text { decreased IOP when compares to prone } \\
\text { positioning for surgery that lasted } 120 \\
\text { minutes or less. } \\
\text { IOP had a slower rate of increase in } \\
\text { subjects in the } 5^{\circ} \text { and } 10^{\circ} \text { prone reverse } \\
\text { Trendelenburg positions compared with } \\
\text { neutral prone position. At } 60 \text { minutes into } \\
\text { surgery, significant differences were } \\
\text { found between the neutral and both } 5^{\circ} \\
\text { (p=.05) and } 10^{\circ}(p=.002) \text { inclination } \\
\text { groups. }\end{array}$ & $\begin{array}{l}\text { Two subjects were excluded due to } \\
\text { battery failure of the tonometer. Small } \\
\text { sample size. } \\
\text { Large degree of variation between } \\
\text { surgeries. Inability to identify the } \\
\text { capacity of reverse trendelenburg } \\
\text { positioning to prevent POVL as the } \\
\text { complication did not occur in any } \\
\text { subjects in the study. Inability to } \\
\text { determine effects on IOP after } 120 \\
\text { minutes }\end{array}$ \\
\hline
\end{tabular}


Emery, S. E., Daffner, S. D., France, J. C., Ellison, M., Grose, B. W., Hobbs, G. R., \& Clovis, N. B. (2015). Effect of head position on intraocular pressure during lumbar spine fusion: A randomized, prospective study. Journal Of Bone \& Joint Surgery, American Volume, 97(22), 1817-1823

\begin{tabular}{|c|c|c|c|c|}
\hline $\begin{array}{l}\text { Baseline } \\
\text { IOP }\end{array}$ & Variables/ Outcomes examined & $\begin{array}{l}\text { IOP measurements in each } \\
\text { interval }\end{array}$ & $\begin{array}{l}\text { Findings } \\
\text { Prone / Reverse Trendelenburg }\end{array}$ & Limitations \\
\hline $\begin{array}{l}\text { Preop sitting } \\
\text { Group I: } 16.93 \\
\pm 3.33 \mathrm{mmHg} \\
\text { Group II: } 16.85 \\
\pm 4.40 \mathrm{mmHg}\end{array}$ & $\begin{array}{l}\text { The duration of surgery was the only factor } \\
\text { associated with a significant rise in IOP } \\
\text { intraoperatively. The change in IOP (the } \\
\text { maximum IOP minus the initial IOP), blood } \\
\text { pressure, and } \mathrm{PCO}_{2} \text { values were examined. The } \\
\text { duration of surgery, amount of crystalloid and } \\
\text { colloids infused, estimated blood loss, } \\
\text { transfusion amount, and the subjects' sex } \\
\text { were recorded. }\end{array}$ & $\begin{array}{l}\text { Preop sitting } \\
\text { Group I: } 16.93 \pm 3.33 \\
\mathrm{mmHg} \\
\text { Group II: } 16.85 \pm 4.40 \\
\mathrm{mmHg} \\
\text { After induction, supine } \\
\text { Group I: } 14.24 \pm 4.96 \\
\text { Group II: } 13.98 \pm 4.82 \\
\text { Initial prone } \\
\text { Group I: } 23.96 \pm 4.93 \\
\text { Group II: } 22.21 \pm 3.87 \\
\text { The average of all IOP } \\
\text { values obtained in prone } \\
\text { position during the } \\
\text { operation was } 27.59 \mathrm{~mm} \\
\text { Hg in Group I and } 23.33 \\
\mathrm{mmHg} \text { in Group II (p }= \\
0.0014)\end{array}$ & $\begin{array}{l}\text { There was no significant difference } \\
\text { between the two groups in the three } \\
\text { initial readings. There was a general } \\
\text { rise in IOP in both Group I and Group } \\
\text { II over time. The mean changes in IOP } \\
\text { measurements were significantly } \\
\text { lower in Group II ( } 9.26 \mathrm{mmHg} \text { ) than } \\
\text { in Group I (13.79 } \mathrm{mmHg}) \text {, with a } \\
\text { difference of } 4.53 \mathrm{mmHg} \text { between } \\
\text { groups ( } \mathrm{p}+0.0074) \text {. } \\
\text { There was also a significant } \\
\text { association between duration of } \\
\text { surgery and change in IOP in each } \\
\text { group. }\end{array}$ & $\begin{array}{l}\text { The cases were } \\
\text { not consecutive } \\
\text { due to the } \\
\text { unavailability of } \\
\text { the } \\
\text { anesthesiologists } \\
\text { and technician. }\end{array}$ \\
\hline
\end{tabular}




\section{Appendix E1}

\section{CASP Screening Questions}

Ozcan, M.S., Praetel, C., Bhatti, M.T., Gravenstein, N., Mahla, M.E., Seubert, C.N. (2004). The effect of body inclination during prone positioning on intraocular pressure in awake volunteers: A comparison of two operating tables. Anesth Analg. 99:1152-8.

\section{Did the study ask a clearly-focused question?}

Yes. The authors set forth to test whether the reverse Trendelenburg position ameliorated the increase in IOP caused by prone positioning. Three different degrees of inclination were compared: horizontal, 10 degree reverse Trendelenburg, and 10 degree Trendelenburg position.

2. Was this a randomized controlled trial (RCT) and was it appropriately so?

No. This study is a randomized crossover study. A randomized crossover study is a method of comparing two or more treatments or interventions in which subjects, on completion of the course of a treatment, are switched to another (PCCRP, 2006). Subjects who volunteered for the study met inclusion and exclusion criteria, and attended two sessions. See Appendix C1 and $\mathrm{E} 1$ for additional session information.

Is it worth continuing? Yes

Detailed Questions

3. Were all of the patients who entered the trial properly accounted for at its conclusion?

Yes. Data was collected on all ten of the subjects, and all ten of the subjects completed the trial.

4. Were patients, health workers, and study personnel 'blind' to treatment?

No. Patients, heath workers and study personnel were not blind to treatment. The participants were awake and would have been able to notice the changes in head elevation of the bed. The study personnel and health workers had to adjust the head of the bed, meaning that they were not blinded. However, this would not have an effect on IOP measurements in each position.

\section{Were the groups similar at the start of the trial?}

Yes. There was only one group of ten subjects. However, they all met the inclusion and exclusion criteria outlined in Appendix C1.

\section{Aside from the experimental intervention, were the groups treated equally?}

Yes. The groups were treated equally. Each subject was placed on the same table for the same period of time with the same degree of head inclination.

\section{How large was the treatment effect?}

IOP was the main outcome measured in the study. Heart rate was measured, but not clinically significant. The authors found that the type of setup used for prone positioning (Jackson table and Wilson frame) had no effect on the IOP increase in prone position. The authors also found that the reverse Trendelenburg position ameliorated the increase in IOP caused by prone positioning. IOP in prone Trendelenbug was $23.8 \mathrm{mmHg}(21.5-26.3 \mathrm{mmHg})$ and IOP in prone reveerse Trendelenburg was $20.3 \mathrm{mmHg}(16.3-22.5 \mathrm{mmHg})$.

\section{How precise was the estimate of the treatment effect?}

The estimate of the treatment effect was precise in that measurements from an applanation tonometer were obtained, and a mean IOP measurement was calculated to determine the effect of head inclination on IOP.

\section{Can the results be applied in your context? (or to the local population?)}

Yes. The authors evaluated the effect of head inclination on IOP, which directly correlates with the purpose of this systematic review. However, the subjects in this study were awake, 
which does not account for anesthetic effects on IOP. However, the study is a good example of the effect of head inclination on IOP.

10. Were all clinically important outcomes considered?

Heart rate, MAP, and IOP were considered in this study, as well as two different table setups: Jackson table and Wilson frame. The authors found that the only IOP was affected by changes in body position and OR table inclination. For the purpose of this review, IOP was the most important outcome, and was considered in this study.

\section{Are the benefits worth the harms and costs?}

Yes. None of the 10 subjects sustained corneal abrasions during or after the study. This study was low risk, and participants were able to position themselves on the OR table, which allowed them to be more comfortable. 


\title{
Appendix E2
}

\author{
CASP Screening Questions
}

Grant, G. P., Szirth, B. C., Bennett, H. L., Huang, S. S., Thaker, R. S., Heary, R. F., \& Turbin, R. E. (2010). Effects of prone and reverse trendelenburg positioning on ocular parameters. Anesthesiology, 112(1), $57-$

65.

\section{Did The Study Ask A Clearly-Focused Question?}

Yes. The authors explained that the purpose of this study was to evaluate the effect of the prone position and a $4^{\circ}$ increase in table inclination over a 5 hour period on IOP as well as ultrasound imaging of the choroid layer and optic nerve diameter.

\section{Was this a randomized controlled trial (RCT) and was it appropriately so? Is it worth continuing?}

This study is a pilot study which tested two interventions at two separate sessions.

\section{Detailed Questions}

3. Were all of the patients who entered the trial properly accounted for at its conclusion?

Yes. All of the subjects were accounted for at the conclusion of the study.

\section{Were patients, health workers, and study personnel 'blind' to treatment?}

The authors do not indicate that the subjects were blind to their treatment. Each subject participated in two sessions: the first in prone position on a horizontal table, and the second in prone position with a 4 degree reverse Trendelenburg position.

\section{Were the groups similar at the start of the trial?}

Ten subjects were included in the trial. There were 5 men and 5 women, ASA I-II, between the ages of 23 and 60 years. Height ranged from 155 to $198 \mathrm{~cm}$, weight ranged from 56 to $147 \mathrm{~kg}$, and BMI ranged from 21.3 to $37.6 \mathrm{~kg} / \mathrm{m} 2$. None of the subjects had a history of hypertension, diabetes, or anemia. One subject had a BMI of 37.6, however according to the authors, because his height was $198.1 \mathrm{~cm}$, his weight was well distributed.

\section{Aside from the experimental intervention, were the groups treated equally?}

In this study, the final 8 subjects concluded their prone session with a rest period of 30 minutes in the supine position with the head of the bed elevated to 30 degrees. This allowed the authors to evaluate changes that may occur in this position in the recovery room. The first two subjects did not experience this 30 minute rest period.

\section{How large was the treatment effect?}

IOP measurements were the main outcome of the study. Ultrasound imaging of the left eye was performed to evaluate choroid thickness and optic nerve diameter. For the purpose of this systematic review, these outcomes were not explored. Blood pressure, visual acuity, heart rate, and oxygen saturation were measured. The authors found that there was a significant effect of time on the increase in IOP in the prone position $(\mathrm{P}<0.05)$. The results showed that IOP at Prone 5 in the reverse Trendelenburg position was $178 \%$ greater than baseline IOP, compared to only a $141 \%$ in the horizontal table position.

\section{How precise was the estimate of the treatment effect?}

IOP was measured using a tonometer. The tonometer averaged four readings per contact, and displayed the mean and standard deviation. Baseline supine measurements were 
taken, and the prone position measurements were taken and displayed as a percentage of baseline IOP.

\section{Can the results be applied in your context? (or to the local population?)}

Yes. The study evaluated the effect of $4^{\circ}$ reverse Trendelenburg on IOP, which directly correlates with the purpose of this systematic review. However, these subjects were awake during the study, which does not provide surgical controls or represent IOP changes under anesthesia.

\section{Were all clinically important outcomes considered?}

As stated above, many treatment effects were measured. For the purpose of this systematic review, IOP was the most important outcome in this study. There was a significant effect of time on IOP, as IOP increase with time spent in prone position. The increase in IOP was greater in the reverse Trendelenburg position compared to the horizontal table position.

\section{Are the benefits worth the harms and costs?}

There were no changes in visual acuity in the subjects after each session. The authors stated that the subjects started to complain of chest discomfort and symptoms of facial and sinus congestion in the final hour. However, symptoms were short lived and resolved after 24 hours. This study was low risk, and the benefits were worth the risks. 


\section{Appendix E3}

\section{CASP Screening Questions}

Carey, T. W., Shaw, K. A., Weber, M. L., \& DeVine, J. G. (2014). Effect of the degree of reverse trendelenburg position on intraocular pressure during prone spine surgery: a randomized controlled trial. Spine Journal, 14(9), 2118-2126 9p.

\section{Did The Study Ask A Clearly-Focused Question?}

Yes. The study's purpose was to assess the affect of table inclination on IOP in patients undergoing prone spine surgery. The authors evaluated three different positions: neutral prone, 5 degree reverse Trendelenburg, and 10 degree reverse Trendelenburg.

\section{Was this a randomized controlled trial (RCT) and was it appropriately so? Is it worth continuing?}

Yes. The authors describe this study as a single center prospective randomized controlled study. 21 subjects undergoing spine surgery at a particular hospital were included in the study. The patients were randomized into one of three table positions: neutral prone, 5 degree reverse Trendelenburg, and 10 degree reverse Trendelenburg. Randomization was performed by TC using a random number generator.

\section{Detailed Questions}

3. Were all of the patients who entered the trial properly accounted for at its conclusion?

Of the 21 subjects who initially entered the study, two were later excluded due to battery failure of the tonometer.

\section{Were patients, health workers, and study personnel 'blind' to treatment?}

The authors stated that the subjects were blinded as to which positioning group they participated. However, the surgeon was not blinded due to the conditions of the study.

\section{Were the groups similar at the start of the trial?}

The subjects in the study met the following inclusion criteria: no pre-existing eye conditions, history of ophthalmic surgery, allergy to latex, or hypersensitivity to topical ester anesthetics. The authors provided no additional information regarding the demographics of the subjects.

\section{Aside from the experimental intervention, were the groups treated equally?}

The groups were treated equally. IOP was measured at the same time intervals for all subjects: preinduction, postinduction, 30 minutes prone, 60 minutes prone, 120 minutes prone. However, there was an unequal number of subjects in each group: 7 subjects in the neutral prone group, 6 subjects in the 5 degree reverse Trendelenburg group, and 6 subjects in the 10 degree reverse Trendelenburg group. 


\section{How large was the treatment effect?}

IOP was measured by a trained CRNA using the Tono-pen XL. IOP was the main treatment effect of the study. MAP, estimated blood loss, and fluid resuscitation were also measured.The authors found that reverse Trendelenburg position decreased IOP when compares to prone positioning for surgery that lasted 120 minutes or less. IOP had a slower rate of increase in subjects in the $5^{\circ}$ and $10^{\circ}$ prone reverse Trendelenburg positions compared with neutral prone position. At 60 minutes into surgery, significant differences were found between the neutral and both $5^{\circ}(p=.05)$ and $10^{\circ}(p=.002)$ inclination groups.

\section{How precise was the estimate of the treatment effect?}

IOP measurements were precise in that measurements were taken by a trained CRNA. The tonometer measurement is an average of four independent readings, and has a probability error of $<5 \%$.

\section{Can the results be applied in your context? (or to the local population?)}

Yes. The authors evaluated the effect of head inclination on IOP, which is of clinical significance to this systematic review. The subjects underwent spine surgery under general anesthesia, which correlates directly with the actual population being discussed in the systematic review.

\section{Were all clinically important outcomes considered?}

Yes. Intraocular pressure measurements served as the primary dependent measure. MAP, EBL, and fluid resuscitation were also measured in this study. However, IOP was the most important outcome in relation to this systematic review.

\section{Are the benefits worth the harms and costs?}

No patients developed visual disturbances postoperatively. One patient experienced a corneal abrasion postoperatively, however there were no other ophthalmic complications. 


\section{Appendix E4}

\section{CASP Screening Questions}

Emery, S. E., Daffner, S. D., France, J. C., Ellison, M., Grose, B. W., Hobbs, G. R., \& Clovis, N. B. (2015). Effect of head position on intraocular pressure during lumbar spine fusion: A randomized, prospective study. Journal Of Bone \& Joint Surgery, American Volume, 97(22), 1817-1823

\section{Did The Study Ask A Clearly-Focused Question?}

Yes. The authors clearly identified the purpose of the study: to measure the effect of 10 degrees of head elevation on IOP in patients undergoing lumbar fusion and to identify intraoperative factors that could affect IOP over several hours of surgery.

\section{Was this a randomized controlled trial (RCT) and was it appropriately so? Is it worth continuing?}

Yes. The authors clearly state that this was a randomized, prospective trial. Subjects met inclusion and exclusion criteria outlined in Appendix C4. Randomization was completed according to a random list of numbers that had been computer generated by a statistician before the study. The authors also indicate that the study was therapeutic Level 1 evidence.

\section{Detailed Questions}

3. Were all of the patients who entered the trial properly accounted for at its conclusion?

No. Sixty-three subjects were enrolled in the study, and eleven of these subjects were dropped from the study after randomization. 6 subjects were dropped from group 1 because of lack of available anesthesiologists or the research coordinator. 5 subjects were dropped from group 2 because of lack of anesthesiologists (3), leak in the endotracheal tube requiring repositioning of the subject (1), and a subject withdrew from the study (1). This resulted in twenty seven subjects in Group I and twenty five subjects in Group II.

\section{Were patients, health workers, and study personnel 'blind' to treatment?}

The authors stated that the subjects were blinded during the study. However, the research coordinator enrolled and assigned all patients to their respective groups, so the research coordinator was not blinded.

\section{Were the groups similar at the start of the trial?}

According to the authors, there were no significant differenced between groups I and II in regard to baseline demographics, which are outlined in Appendix C4.

\section{Aside from the experimental intervention, were the groups treated equally?}

Yes. According to the authors, to provide consistency, a small group of four anesthesiologists were involved in the study and managed all patients. Also, there was only one technician who obtained all IOP measurements with the applanation tonometer. IOP was measured at the same intervals with each group. 


\section{How large was the treatment effect?}

IOP was the main measure in the study. The mean changes in IOP were lower in group II then in Group I. Other variables that were measured were arterial and venous blood pressure, PCO2, duration of surgery, amount of crystalloid and colloid infusion, estimated blood loss, transfusion amount, and the subject's gender. There was a general rise in IOP over time in both groups I and II. The authors found there was no correlation between colloid and crystalloid amounts, estimated blood loss, transfusion amounts, and gender with the rise in IOP over time.

\section{How precise was the estimate of the treatment effect?}

The estimate of the treatment effect was precise in that only one data technician obtaining IOP measurements. IOP was measured in each eye, and data was presented as a two-eye average IOP, or mean of both ocular readings per patient.

\section{Can the results be applied in your context? (or to the local population?)}

Yes. The results directly correlate with the population targeted in this systematic review. The subjects underwent spine surgery under general anesthesia, and therefore the data is a good representation of the effect of head inclination on subjects undergoing spine surgery under general anesthesia.

\section{Were all clinically important outcomes considered?}

The most important outcome for the purpose of this systematic review is IOP. IOP was the main measure in this study. Other measures included blood pressure, PCO2, duration of surgery, amount of crystalloid and colloid infusion, estimated blood loss, transfusion amount, and gender.

\section{Are the benefits worth the harms and costs?}

None of the subjects developed vision loss or cervical-spine related complications. One patient developed a mild corneal abrasion that resolved in twenty-four hours. Therefore, the benefits of the study outweigh the risks. 